\title{
Deactivation of Ni-MoS2 by bio-oil impurities during hydrodeoxygenation of phenol and octanol
}

Mortensen, Peter Mølgaard; Gardini, Diego; Damsgaard, Christian Danvad; Grunwaldt, Jan-Dierk; Jensen, Peter Arendt; Wagner, Jakob Birkedal; Jensen, Anker Degn

Published in:

Applied Catalysis A: General

Link to article, DOI:

10.1016/j.apcata.2016.06.002

Publication date:

2016

Document Version

Peer reviewed version

Link back to DTU Orbit

Citation $(A P A)$ :

Mortensen, P. M., Gardini, D., Damsgaard, C. D., Grunwaldt, J-D., Jensen, P. A., Wagner, J. B., \& Jensen, A. D. (2016). Deactivation of Ni-MoS by bio-oil impurities during hydrodeoxygenation of phenol and octanol. Applied Catalysis A: General, 523, 159-470. https://doi.org/10.1016/j.apcata.2016.06.002

\section{General rights}

Copyright and moral rights for the publications made accessible in the public portal are retained by the authors and/or other copyright owners and it is a condition of accessing publications that users recognise and abide by the legal requirements associated with these rights.

- Users may download and print one copy of any publication from the public portal for the purpose of private study or research.

- You may not further distribute the material or use it for any profit-making activity or commercial gain

- You may freely distribute the URL identifying the publication in the public portal 


\section{Accepted Manuscript}

Title: Deactivation of Ni-MoS 2 by bio-oil impurities during hydrodeoxygenation of phenol and octanol

Author: Peter M. Mortensen Diego Gardini Christian D. Damsgaard Jan-Dierk Grunwaldt Peter A. Jensen Jakob B. Wagner Anker D. Jensen

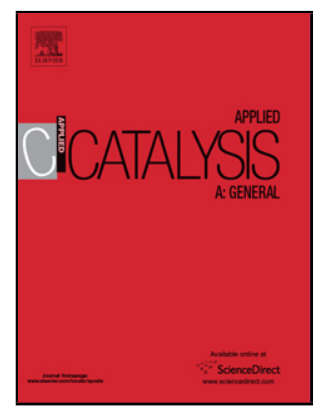

PII: S0926-860X(16)30314-3

DOI:

Reference: http://dx.doi.org/doi:10.1016/j.apcata.2016.06.002

To appear in: APCATA 15896

Received date: Applied Catalysis A: General

Revised date:

$15-2-2016$

Accepted date:

Please cite this article as: Peter M.Mortensen, Diego Gardini, Christian D.Damsgaard, Jan-Dierk Grunwaldt, Peter A.Jensen, Jakob B.Wagner, Anker D.Jensen, Deactivation of Ni-MoS2 by bio-oil impurities during hydrodeoxygenation of phenol and octanol, Applied Catalysis A, General http://dx.doi.org/10.1016/j.apcata.2016.06.002

This is a PDF file of an unedited manuscript that has been accepted for publication. As a service to our customers we are providing this early version of the manuscript. The manuscript will undergo copyediting, typesetting, and review of the resulting proof before it is published in its final form. Please note that during the production process errors may be discovered which could affect the content, and all legal disclaimers that apply to the journal pertain. 


\section{Deactivation of Ni-MoS 2 by bio-oil impurities during}

\section{hydrodeoxygenation of phenol and octanol}

Peter M. Mortensena, Diego Gardinib, Christian D. Damsgaardb,c, Jan-Dierk Grunwaldt,

Peter A. Jensena, Jakob B. Wagner ${ }^{b}$ \& Anker D. Jensen ${ }^{\text {* }}$

aDepartment of Chemical and Biochemical Engineering, Technical University of

Denmark, Søltofts Plads, Building 229, DK-2800 Lyngby, Denmark

${ }^{b}$ Center for Electron Nanoscopy, Technical University of Denmark, Fysikvej,Building 307, DK-2800 Lyngby, Denmark

${ }^{c}$ CINF, Department of Physics, Technical University of Denmark, Fysikvej,Building 312, DK-2800 Lyngby, Denmark

${ }^{d}$ Institute for Chemical Technology and Polymer Chemistry, Karlsruhe Institute of Technology (KIT), Engesserstrasse 20, D-79131 Karlsruhe, Germany

${ }^{*}$ Corresponding author. Tel.: +4545252841 fax: +454588 2258. E-mail address:

aj@kt.dtu.dk (A.D. Jensen). 


\section{Graphical abstract}

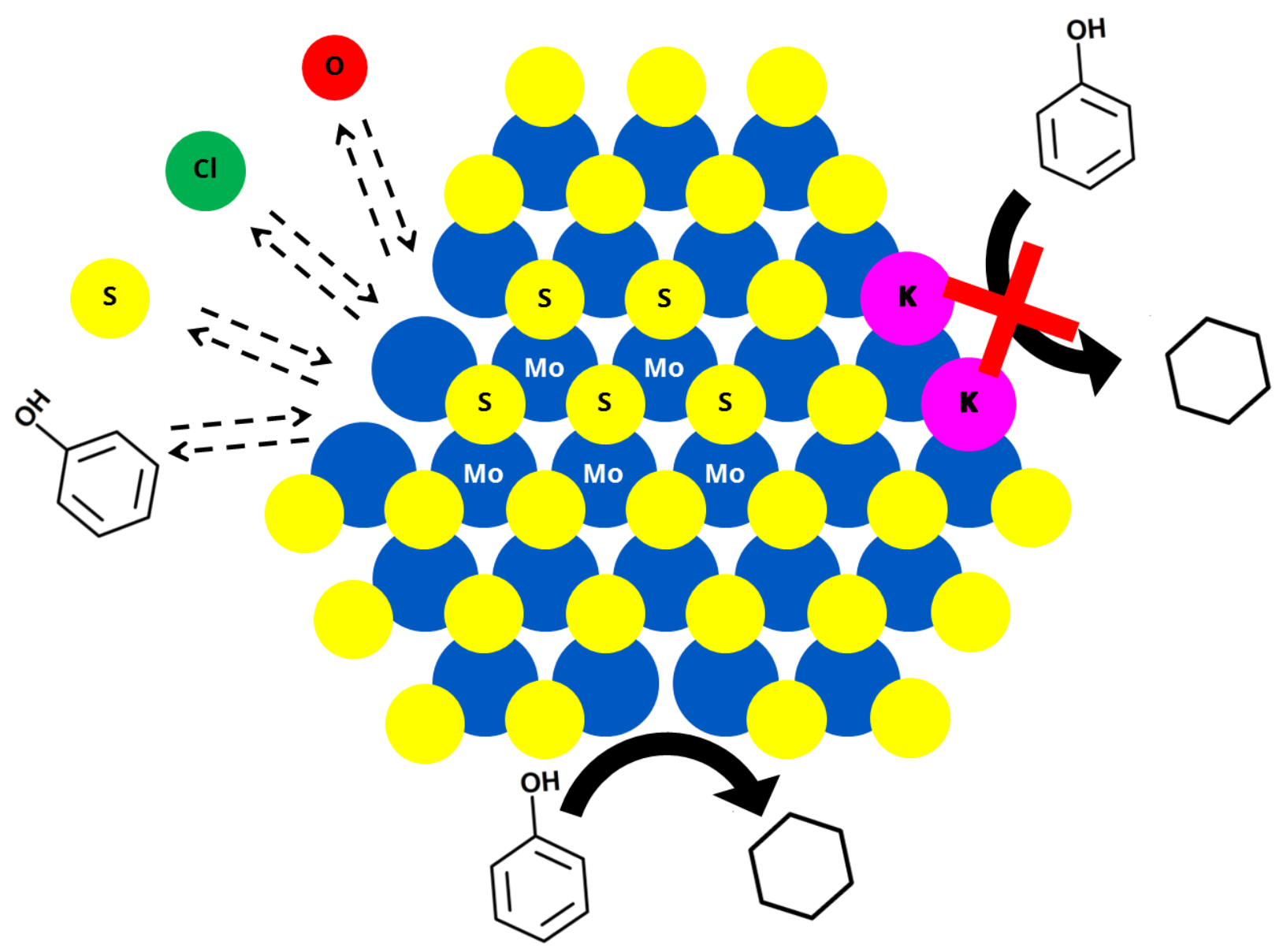

\section{Highlights}

- Impurities as $\mathrm{Cl}, \mathrm{S}$, and $\mathrm{K}$ found in bio-oil will deactivate or inhibit MoS2-type catalyst by competing for the active sites

- MoS2-based catalysts will produce sulfur containing hydrocarbons during HDO, but these can be removed again if a sufficiently high residence time is used enabling desulfurization of the product

- Chlorine binds more strongly to the active sites of $\mathrm{MoS}_{2}$ based catalysts compared to $\mathrm{H}_{2} \mathrm{O}$ and $\mathrm{H}_{2} \mathrm{~S}$, while $\mathrm{K}$ irreversibly deactivates the catalyst 


\section{Abstract}

The stability of $\mathrm{Ni}-\mathrm{MoS}_{2} / \mathrm{ZrO}_{2}$ toward water, potassium, and chlorine containing compounds during hydrodeoxygenation (HDO) of a mixture of phenol and 1-octanol was investigated in a high pressure gas and liquid continuous flow fixed bed setup at $280^{\circ} \mathrm{C}$ and 100 bar. To maintain the stability of the catalyst, sufficient co-feeding of a sulfur source was necessary to avoid oxidation of the sulfide phase by oxygen replacement of the edge sulfur atoms in the $\mathrm{MoS}_{2}$ structure. However, the addition of sulfur to the feed gas resulted in the formation of sulfur containing compounds, mainly thiols, in the oil product if the residence time was too low. At a weight hourly space velocity (WHSV) of 4.9 $\mathrm{h}^{-1}$ the sulfur content in the liquid product was $980 \mathrm{ppm}$ by weight, but this could be decreased to $5 \mathrm{ppm}$ at a WHSV of $1.4 \mathrm{~h}^{-1}$. A high co-feed of sulfur was needed when water was present in the feed and the $\mathrm{H}_{2} \mathrm{O} / \mathrm{H}_{2} \mathrm{~S}$ molar ratio should be below ca. 10 to maintain a decent stability of the catalyst. Chlorine containing compounds caused a reversible deactivation of the catalyst when co-fed to the reactor, where the catalytic activity could be completely regained when removing it from the feed. Commonly, chlorine, $\mathrm{H}_{2} \mathrm{O}$, and $\mathrm{H}_{2} \mathrm{~S}$ all inhibited the activity of the catalyst by competing for the active sites, with chlorine being by far the strongest inhibitor and $\mathrm{H}_{2} \mathrm{~S}$ and $\mathrm{H}_{2} \mathrm{O}$ of roughly the same strength. Dissimilar, potassium was a severe poison and irreversibly deactivated the catalyst to $<5 \%$ degree of deoxygenation when impregnated on the catalyst in a stoichiometric ratio relative to the active metal. This deactivation was a result of adsorption of potassium on the edge vacancy sites of the $\mathrm{MoS}_{2}$ slabs.

Keywords: Bio-oil, Hydrodeoxygenation, HDO, Stability, Deactivation, Characterization

\section{Introduction}

It has become generally accepted that the oil reserves are depleting due to increased use of fossil fuels throughout the last 100 years [1]. In addition, this has led to a rising 
concentration of $\mathrm{CO}_{2}$ in the atmosphere, which is correlated to a greenhouse effect leading to global warming on the Earth [2]. These aspects raise concerns and give incitement for investigation of alternative ways for production of fuels, as well as bulk chemicals. A prospective path to these could be biomass based, as this constitutes a carbon containing resource which can be reproduced within a relatively short time $[3,4]$.

A challenge with biomass is that it has a relatively low energy- and mass-density. This makes transport expensive and constrains its utilization [5]. Hence, it has been suggested to convert biomass into bio-oil by flash pyrolysis and subsequently upgrade this to fuel by hydrodeoxygenation, which is applicable with practically any type of biomass [6]. Hydrodeoxygenation (HDO) constitutes a prospective upgrading route for bio-oil. This is a high pressure catalytic upgrading process where hydrogen is used for exclusion of oxygen [6].

One of the major challenges in the HDO process is to develop an active catalyst which also is sufficiently stable. The latter aspect is challenged by the bio-oil's tendency to form coke and its content of alkali metals, sulfur, chlorine, phosphorus, and other impurities [68].

Traditional hydrotreating catalysts, such as $\mathrm{Co}_{-} \mathrm{MoS}_{2}$ and $\mathrm{Ni}-\mathrm{MoS}_{2}$, have been among the most tested catalysts for HDO of bio-oil [6,9-14]. This group of catalysts is already industrially established for hydrodesulfurization (HDS) of crude oil [15-18]. In HDS, the activity of the catalyst has been linked to the availability of edge sites on the MoS2 slabs with two adsorption sites for the sulfur containing compound on vacancy sites and hydrogen on Mo-S [16,19-22]. As the mechanisms for HDS and HDO are similar, this type of sites are believed to be the active sites for HDO as well $[23,24]$. Promotion with either $\mathrm{Co}$ or $\mathrm{Ni}$ increases the availability of vacancy sites by lowering the Mo-S bond energy $[16,18,20,25,26]$.

Long term stability of $\mathrm{MoS}_{2}$ based catalysts during HDO remains to be thoroughly investigated. One of the concerns raised, is the requirement for co-feeding sulfur in order to retain the active sulfide form of the catalyst, but this could potentially contaminate the otherwise sulfur scant bio-oil $[6,25,27,28]$. Additionally, little is known about the influence of bio-oil impurities on the catalyst stability. 
In the present work, the stability of $\mathrm{Ni}-\mathrm{MoS}_{2} / \mathrm{ZrO}_{2}$ is investigated in a series of prolonged continuous flow reactor experiments. The stability was evaluated in the presence of $\mathrm{H}_{2} \mathrm{~S}, \mathrm{H}_{2} \mathrm{O}$, potassium and organically bound chlorine. For this purpose, a biooil model system of phenol in 1-octanol was used. Phenol and phenolic derivatives are a fairly abundant part of bio-oil constituting up to $15 \mathrm{wt} \%$ [6], which are quite persistent oxycompounds to deoxygenate [29]. 1-octanol was chosen partly as a solvent for the phenol, but also to simulate some of the more easily accessible oxygen functionalities which are also found in bio-oil [30], as simple alcohols may constitute up to $4 \mathrm{wt} \%$ of the bio-oil [6]. $\mathrm{Ni}-\mathrm{MoS}_{2} / \mathrm{ZrO}_{2}$ was chosen as catalyst, as promotion by nickel previously has been shown to be slightly superior to cobalt promotion for $\mathrm{HDO}$ purposes $[9,25]$ and $\mathrm{ZrO}_{2}$ was previously found as a suitable support for HDO [31-35] and does apparently not suffer from the instability in high concentration of water, as reported for the conventionally used $\gamma-\mathrm{Al}_{2} \mathrm{O}_{3}$ support for hydrotreating catalysts $[9,36,37]$.

\section{Experimental}

\subsection{Catalyst synthesis}

$\mathrm{Ni}-\mathrm{MoO}_{3} / \mathrm{ZrO}_{2}$ (3 wt\% Ni, $15 \mathrm{wt} \% \mathrm{Mo}$ ) was prepared by sequential incipient wetness impregnation. The zirconia was supplied by Saint-Gobain NorPro, type SZ6*152 containing $3.3 \% \mathrm{SiO}_{2}$, a specific surface area of $140 \mathrm{~m}^{2} / \mathrm{g}$, and a pore volume of $0.32 \mathrm{ml} / \mathrm{g}$. In the synthesis, the catalyst precursor was dissolved in water equivalent to the pore volume of the support and subsequently mixed with the support. $15 \mathrm{wt} \%$ Mo was initially impregnated from a solution of $\left(\mathrm{NH}_{4}\right)_{6} \mathrm{Mo}_{7} \mathrm{O}_{24} \cdot 4 \mathrm{H}_{2} \mathrm{O}$ (Sigma-Aldrich, $\geq 97.0 \%$ ) in water on $\mathrm{ZrO}_{2}$ (sieve fraction 300-600 $\mu \mathrm{m}$ ) and then dried overnight at $70^{\circ} \mathrm{C}$. $\mathrm{Ni}\left(\mathrm{NO}_{3}\right) \cdot 3 \mathrm{H}_{2} \mathrm{O}$ (SigmaAldrich, $\geq 96.0 \%$ ) was dissolved in water and impregnated on the dry Mo-loaded catalyst to a level of $3 \mathrm{wt} \% \mathrm{Ni}$ and then dried at $70^{\circ} \mathrm{C}$ overnight. Finally, the catalyst was calcined by heating to $400^{\circ} \mathrm{C}$ at a rate of $10^{\circ} \mathrm{C} / \mathrm{min}$ in air and held there for $4 \mathrm{~h}$.

The catalysts were sulfided in the continuous flow reactor setup prior to testing by initially heating a portion of the catalyst to $200^{\circ} \mathrm{C}$ in $\mathrm{N}_{2}$ and then heating at a rate of $5^{\circ} \mathrm{C} / \mathrm{min}$ to $350^{\circ} \mathrm{C}$ in a flow of $800 \mathrm{Nml} / \mathrm{min} \mathrm{H}_{2}$ and $0.2 \mathrm{ml} / \mathrm{min}$ dimethyl disulfide (DMDS, Sigma-Aldrich, $\geq 99 \%$ ) at atmospheric pressure. Sulfidation was carried out for $2.5 \mathrm{~h}$ at 
$350^{\circ} \mathrm{C}$. Assuming complete decomposition of DMDS to $\mathrm{H}_{2} \mathrm{~S}$ the feed concentration of the gas would be: $12 \% \mathrm{H}_{2} \mathrm{~S}, 12 \% \mathrm{CH}_{4}$, and $76 \% \mathrm{H}_{2}$.

\subsection{Catalyst testing}

The experiments were performed in a high pressure gas and liquid continuous flow packed bed setup. The setup was thoroughly described in previously published work from our group [7].

$2.5 \mathrm{~g}$ of catalyst sieved to $300-600 \mu \mathrm{m}$ was mixed with $7.5 \mathrm{~g}$ glass beads of sieve fraction 210-250 $\mu \mathrm{m}$ to dilute the catalyst bed and thereby obtain better control of the exothermic reactions. The glass bead/catalyst mixture rested on a quartz wool plug in the reactor, which was supported on a crossbar in the reactor.

Evaluation of transport limitations by Mears criterion [38] for the given sieve fraction of catalyst particles revealed that the system was not limited by boundary layer diffusion. On the contrary, internal diffusion limitation was present in some of the experiments. Specifically, conversion of 1-octanol in the most active cases seemed limited. Detailed information of the evaluation of the transport limitations in the different configurations investigated in this study can be found in the electronic supporting information (ESI).

A feed mixture of $50 \mathrm{~g} / \mathrm{l}$ phenol (Sigma-Aldrich, $\geq 99 \%$ ) and $2-5$ vol\% DMDS in 1octanol (Sigma-Aldrich, $\geq 99 \%$ ) was used as bio-oil model compound system and generally fed at a flow of $0.2 \mathrm{ml} / \mathrm{min}$. 1-octanol was chosen as co-reactant (despite it is not a usual bio-oil component) due to its relative high boiling point $\left(195^{\circ} \mathrm{C}\right.$ at ambient pressure [39]) and ability to mix with phenol in a single homogenous phase. Hydrogen (AGA, 99.9\%) and nitrogen (AGA, 99.9\%), as internal standard, were fed to the reactor at a flow of respectively $200 \mathrm{Nml} / \mathrm{min}$ and $50 \mathrm{Nml} / \mathrm{ml}$, corresponding to 5 times the stoichiometric hydrogen requirement of the feed oil. During the reactions, the reactor was maintained at a constant pressure of 100 bar and the set point temperature of the reactor furnace was $280^{\circ} \mathrm{C}$.

In the experiments with varying weight hourly space velocity (WHSV), the $\mathrm{H}_{2} /$ oil feed ratio was kept constant at $1000 \mathrm{Nml} / \mathrm{ml}$, and $\mathrm{N}_{2}$ was not co-fed in these experiments. Each feed rate was kept for at least $8 \mathrm{~h}$ to ensure representative product samples. 
The catalytic activity in an empty reactor was tested in connection with previous work on the same setup as used in this study and was found insignificant [7]. Repeatability was also tested in this study and a relative standard deviation for hydrodeoxygenation activity of $9 \%$ was found from a threefold repetition on the setup.

\subsection{Product analysis}

The liquid product was analyzed using a Shimadzu gas chromatograph GC-MS/FIDQP2010 UltraEi fitted with a Supelco Equity-5 column. Identification was made on mass spectrometer (MS) and quantification was done using a flame ionization detector (FID). External standards were prepared for phenol, cyclohexanol, cyclohexane, methanol, 1octanol, and octane. The concentration of the remaining peaks were calculated from the FID on the basis of the effective carbon number method [40], where the concentration of a compound was calculated as:

$$
C_{i}=C_{r e f} \cdot \frac{A_{i} \cdot v_{e f f, r e f}}{A_{r e f} \cdot v_{e f f, i}}
$$

Here $C$ is the concentration, $A$ the area of the peak in the FID spectrum, and $v_{e f f}$ the effective carbon number. Index $i$ refers to the compound with the unknown concentration and index ref refers to a reference compound where the concentration is known. In all calculations using Eq. 1, octane was used as reference. The effective carbon number was taken from the review by Schofield [40].

The weight hourly space velocity was calculated as:

$$
W H S V=v_{0} \cdot \frac{\rho_{\text {feed }}}{m_{\text {cat }}}
$$

Here $v_{0}$ is the volumetric feed flow, $\rho_{\text {feed }}$ the density of the liquid feed, and $m_{\text {cat }}$ the mass of catalyst used.

The conversion $(X)$ was calculated for both phenol and 1-octanol as:

$$
X=\left(1-\frac{C_{o u t, i} \cdot v_{o u t}}{C_{0, i} \cdot v_{0}}\right) \cdot 100 \%
$$


Here $C_{i}$ is the concentration of compound $i$ and $v$ is the volumetric flow. Index out refers to the conditions after the reactor, index 0 refers to the inlet conditions, and $i$ refers to the compound of relevance.

The yields $\left(Y_{i}\right)$ of relevant products were calculated as:

$$
Y_{i}=\frac{C_{\text {out }, i} \cdot v_{\text {out }}}{C_{0, j} \cdot v_{0}} \cdot 100 \%
$$

Index $i$ is here referring to the compound of relevance leaving the reactor and index $j$ is referring to the initial reactant, phenol or 1-octanol.

The selectivity $\left(S_{i}\right)$ of a compound $(i)$ was calculated as:

$$
S_{i}=\frac{Y_{i}}{X} \cdot 100 \%
$$

The degree of deoxygenation (DOD) was calculated as:

$$
D O D=\left(1-\frac{F_{O, o u t}}{F_{O, \text { in }}}\right) \cdot 100 \%
$$

Here $F_{O}$ is the molar flow rate of oxygen (excluding water) either in or out of the reactor.

The sulfur content on a weight basis $\left(w_{S}\right)$ was quantified from the sulfur containing compounds found by GC-FID as:

$$
w_{S}=\frac{\sum C_{i} \cdot M_{S}}{\rho_{\text {liquid }}}
$$

Where $C_{i}$ is the concentration of a sulfur containing hydrocarbon (mostly thiols and small fraction of thioethers), $M_{S}$ the molecular weight of sulfur, and $\rho_{\text {liquid }}$ is the density of the oil (estimated as the density of 1-octanol).

To make an additional quantification of the activity of the catalyst, first order rate constants for both phenol and 1-octanol conversion were calculated assuming plug flow in the reactor:

$$
k_{i}=\frac{v_{0}}{W} \cdot \ln \left(\frac{1}{1-X_{i}}\right)
$$

Here $k_{i}$ is the rate constant of reaction $i$ and $W$ the mass of catalyst. Previous work has shown that HDO of guaiacol, anisole, and phenol can be approximated with $1^{\text {st }}$ order kinetics [35,41-43]. 


\subsection{Catalyst characterization}

Elemental analysis of the catalysts was performed using inductively coupled plasma atomic emission spectroscopy (ICP-OES). For the analysis, the samples were crushed and melted together with potassium pyrosulfate. This was dissolved in a solution of water and $\mathrm{HCl}$ and then analyzed by plasma emission spectroscopy. The instrument was calibrated with certified standards for the elements analyzed for.

Powder X-Ray Diffraction (XRD) measurements were carried out using a PANalytical $X '$ Pert PRO diffractometer in a Bragg-Brentano Theta-Theta geometry. The catalysts were analyzed in a $10^{\circ}<\theta<70^{\circ}$ range using a monochromatic $\mathrm{Cu}-\mathrm{K} \alpha$ radiation $(\lambda \approx 1.5418 \AA$ ). XRD data treatment was carried out using PANalytical HighScore Plus 3.0.5 software.

Bright Field (BF) micrographs were acquired using a FEI Titan 80-300 transmission electron microscope (TEM) operated at $300 \mathrm{kV}$ and EDX elemental maps were acquired using a cubed FEI Titan operated at $120 \mathrm{kV}$. For this purpose, the corresponding catalyst powders were crushed in a mortar and dry dispersed on a non-coated gold TEM grid. Fitting of EDX spectra was carried out using OriginPro 2015 software. Details can be found in the ESI.

\section{Results and Discussion}

\subsection{Characterization of the as-sulfided catalyst by electron microscopy and $X$-ray diffraction}

In order to verify the intended synthesis of $\mathrm{Ni}-\mathrm{MoS}_{2} / \mathrm{ZrO}_{2}$ and study the distribution of the active phase on the zirconia support, a characterization approach involving the combination of electron microscopy and X-ray diffraction was used on a freshly sulfide sample of $\mathrm{Ni}-\mathrm{MoS}_{2} / \mathrm{ZrO}_{2}$.

$\mathrm{XRD}$ of the as-sulfided catalyst showed strong reflections belonging to the crystalline $\mathrm{ZrO}_{2}$ support and minor reflections that were indexed as $\mathrm{MoS}_{2}, \mathrm{NiS}$ and $\mathrm{Ni}$ (see Figure 1(a)). The presence of crystalline $\mathrm{Ni}$ species probably represents leftover $\mathrm{Ni}$ from the synthesis procedure and the following reductive sulfidation procedure. The effective 
sulfidation of Mo oxide precursor species was furthermore confirmed by the identification of lamellar structures in BF-TEM imaging (see Figure 1(b)). The measured interlayer distance was $0.62 \mathrm{~nm}$, matching $\mathrm{MoS}_{2} c$ stacking distance [44].

In order to univocally identify the active phase of the catalyst, STEM-EDX elemental maps were acquired, as mass-thickness contrast in bright-field imaging was found to be insufficient. Figure 2 shows two characteristic areas of an as-sulfided catalyst. In both cases, elemental maps II, III and IV can be compared in order to evaluate the spatial distribution of $\mathrm{S}, \mathrm{Zr}$ and Mo elements, respectively. Overall, $\mathrm{MoS}_{2}$ structures were found to effectively cover the $\mathrm{ZrO}_{2}$ support (Figure 2(a)) forming in some cases areas of higher density (Figure 2(b)).

Further elemental maps were acquired in order to study the distribution of nickel species in the as-sulfided catalyst. As Figure 3 shows, Ni X-ray emission lines together with those stemming from Mo were detected when analyzing a portion of the sample containing $\mathrm{MoS}_{2}$ structures, showing the effective incorporation of the promoter in the layered sulfide and the formation of the desired $\mathrm{Ni}_{-} \mathrm{MoS}_{2}$ active phase. Furthermore, Ni-rich nanoparticles were identified (Figure 3(b)), in accordance with the results of the XRD analysis (see Figure 1(a)).

\subsection{The effect of residence time}

To begin with the effect of residence time was investigated for HDO of phenol in 1octanol, with a co-feed of 2 vol\% DMDS (corresponding to 8170 ppm $\mathrm{H}_{2} \mathrm{~S}$ in the gas feed). The DMDS was added to ensure that the catalyst remained in the sulfided form. The conversion of 1-octanol and phenol and yields of cyclohexane, cyclohexene, octane, and octene are shown together with the sulfur content calculated from organic sulfur compounds in the product as a function of the WHSV in Figure 4. For 1-octanol, 
decreasing the WHSV increased the conversion, with octane as the primary product. 1octene was an important intermediate with a selectivity of $12 \%$ at a WHSV of $4.9 \mathrm{~h}^{-1}$, but decreasing to $0 \%$ at a WHSV of $1.4 \mathrm{~h}^{-1}$. Thus, HDO of 1 -octanol over this catalyst proceeds by a dehydration reaction scheme, producing 1-octene, which subsequently reacts with hydrogen to form octane as the final product, as shown in Figure 5.

For HDO of phenol, cyclohexane was observed as the primary product at all WHSV's, but also benzene (up to $5 \%$ selectivity), cyclohexanol (up to $18 \%$ selectivity), and cyclohexene (up to $41 \%$ selectivity) were detected. HDO of phenol can take place by two paths as summarized in Figure 5: a direct deoxygenation of phenol to benzene, followed by hydrogenation to cyclohexane, or an initial hydrogenation of phenol to cyclohexanol followed by dehydration to cyclohexene and then hydrogenation to cyclohexane. The preferred reaction path depends on the catalyst and reaction conditions [45-51]. Apparently, the hydrogenation path is preferred under the given conditions in this work, as evidenced by the high fraction of cyclohexanol and cyclohexene at especially the high WHSV. Note that thermodynamic equilibrium between cyclohexane and benzene is completely displaced towards cyclohexane at the given conditions, and this will thus also influence the product mixture.

Besides the hydrocarbon products, also 1-octanethiol and cyclohexanethiol were formed. The selectivity toward 1-octanethiol and cyclohexanethiol dropped from $3.1 \%$ and $0.8 \%$, respectively, at $4.9 \mathrm{~h}^{-1}$ to $<0.1 \%$ at $1.4 \mathrm{~h}^{-1}$, as shown in Figure $4(\mathrm{~b})$. These compounds are most likely formed by side reactions by saturation of the double bonds in 1-octene and cyclohexene with $\mathrm{H}_{2} \mathrm{~S}$ (see Figure 5), as both are present in high concentrations at the higher WHSV's. However, as the Ni-Mo catalyst also acts as a HDS catalyst [15-18], the thiols are removed again. Consequently, the sulfur content of the product oil amounted to less than $5 \mathrm{ppm}_{\mathrm{w}}$ at the lowest WHSV tested (see Figure 4(b)), which was a result of removing the formed thiols and removing the intermediates (alkenes) which enabled the formation of the thiols. In conclusion, sufficiently high residence times 
are a requirement when using Ni-MoS2 type catalysts to perform HDO as this enables the HDS reaction pathway to proceed sufficiently as well.

\subsection{The effect of sulfur containing components}

The stability of the $\mathrm{Ni}-\mathrm{MoS}_{2} / \mathrm{ZrO}_{2}$ catalyst and the influence of the sulfur source were investigated in two experiments: one with 0.3 vol\% 1-octanethiol in the feed and one with 2 vol\% DMDS in the feed, corresponding to respectively $280 \mathrm{ppm}$ and $8170 \mathrm{ppm} \mathrm{H}_{2} \mathrm{~S}$ in the gas feed, assuming complete decomposition of the feed sulfur compounds. The first case with thiols is representative of the type of sulfur containing components which can be present in bio-oil (thiols are present in naturally occurring proteins [52]) and concentration that could be expected in bio-oil [53]. The second case was an attempt to improve the catalyst stability. The conversion of phenol and 1-octanol in these experiments are summarized in Figure 6.

In the case with 0.3 vol\% 1-octanethiol in the feed, the activity steadily decreased throughout the $110 \mathrm{~h}$ of testing. The 1 -octanol conversion decreased from $78 \%$ to $49 \%$ and the phenol conversion decreased from $56 \%$ to $21 \%$ (see Figure 6(a)). In comparison, adding 2 vol\% DMDS to the feed resulted in a significantly better stability, as the 1-octanol conversion only dropped from $95 \%$ to $88 \%$ over $96 \mathrm{~h}$ of testing and the phenol conversion dropped from $36 \%$ to $19 \%$ in the same time frame (see Figure $6(b)$ ).

The concentration of thiols in the liquid product increased from 13 ppmw sulfur in the case co-feeding 0.3 vol\% 1 -octanethiol to 381 ppm $_{w}$ in the case co-feeding 2 vol\% DMDS. Thus, the sulfur concentration in the liquid product will be dependent on the residence time (as discussed in Section 3.2) and also the concentration of sulfur in the feed.

Analysis of sulfur on the spent catalyst with ICP-OES revealed that the sulfur content in the case co-fed with 0.3 vol\% 1-octanethiol had decreased to $7.5 \mathrm{wt} \%$, compared to 10.9 wt\% on the as-sulfided catalyst (see Table 1). In comparison, the catalyst co-fed with 2 vol\% DMDS had a content of 8.4 wt\% sulfur on the spent catalyst. Thus, both catalysts lost sulfur during operation, but the case co-feeding 1-octanethiol lost significantly more. The theoretical sulfur content as $\mathrm{MoS}_{2}$ on the fresh catalyst should be $9.1 \mathrm{wt} \%$, compared to 
$10.9 w t \%$ in Table 1. This indicates that some of the initial sulfur content could not be present as sulfide but other more loosely adsorbed sulfur species on the as-sulfided catalyst. Hence this is rather rapidly removed.

Additional analysis of the Mo and Ni content by ICP-OES on the catalyst did not indicate metal leaching in any significant degree from the catalyst, as the molar Ni/Mo ratio was constant within the standard deviation for all the analyzed samples in Table 1.

In addition to ICP-OES, more local and qualitative investigations were carried out by means of STEM-EDX mapping of as-sulfided and spent Ni-MoS$/ 2 \mathrm{ZrO}_{2}$ catalysts tested with different sources of sulfur in the feed and varying $\mathrm{H}_{2} \mathrm{O} / \mathrm{H}_{2} \mathrm{~S}$ feed ratios. For each catalyst the ratio between $\mathrm{Mo} \mathrm{Ka}_{1,2}$ and $\mathrm{S} \mathrm{Ka} \alpha_{1,2} \mathrm{X}$-ray emission peaks from Ni-MoS $\mathrm{S}_{2}$ rich areas was calculated by multiple Gaussian fit of portions of the EDX spectrum and is representative of the relative concentration of the two elements in the sample. A more detailed explanation of the quantification is given in the ESI.

As Figure 7 shows, active phase rich areas of the catalyst co-fed with 0.3 vol\% 1 octanethiol presented the highest Mo/S X-ray emission ratio, indicating a more severe loss of sulfur during catalytic testing. On the other hand, in the case of co-feeding 2 vol\% DMDS the ratio was found to be similar to the fresh catalyst, showing that consistently less sulfur is lost from the sample. It is important to point out that these ratios are representative of the sole active phase composition and hence cannot be directly compared to the elemental analysis measurements shown in Table 1, accounting for the whole catalyst composition. However, the result of this EDX quantification follows in a qualitative way the trend of the ICP-OES analysis and is complementary to it, confirming that the variation of sulfur level in the spent catalysts is connected to a loss of sulfur from the active phase.

Additionally, the ICP-OES analysis revealed that the tendency for the deposition of carbonaceous species was low on both catalysts with less than $4 \mathrm{wt} \%$ carbon at end of run. Roughly half of this was already deposited during sulfidation, as $2 \mathrm{wt} \%$ carbon was 
found on a freshly sulfided catalyst (see Table 1). Note that Wang et al. [54] observed severe deactivation by carbonaceous species on a NiMo/ $/-\mathrm{Al}_{2} \mathrm{O}_{3}$ for hydrotreating of bio-oil at ca. $300^{\circ} \mathrm{C}$ and 100 bar in a plug flow reactor. They also found $21.4 \mathrm{wt} \%$ carbon after $240 \mathrm{~h}$ TOS. The amount of carbon deposit in the current study is significantly lower and has in the following analysis been disregarded. Nevertheless, carbon formation remains an important mechanism in HDO of bio-oil to be further pursued especially at higher temperatures.

The location of carbonaceous deposits on the catalysts from the current study were identified by means of electron microscopy in multiple areas of the catalyst co-fed with 0.3 vol\% 1-octanethiol. STEM-EDX mapping revealed the presence of carbon containing flakes characterized by a lamellar structure with an interlayer distance of $1.96 \mathrm{~nm}$ (see Figure 8). The origin and the nature of these structures remain at present unknown; however, their presence could be the main reason for the higher carbon content measured for this catalyst by ICP-OES (see Table 1).

The combination of ICP-OES elemental analysis (see Table 1) and more local EDX peak area analysis (see Figure 7) indicates that feeding insufficient sulfur will result in a depletion of sulfur of the sulfide phase. Previous work has also shown that oxygen atoms from the HDO reaction can replace framework $S$-atoms in the MoS 2 with insufficient sulfur in the feed [47,55-58]. The natural content of sulfur in bio-oil does not appear sufficient for sustaining the catalyst in the active form during operation and addition of DMDS/ $\mathrm{H}_{2} \mathrm{~S}$ is consequently recommended during HDO of a real bio-oil feed.

Comparing the initial activity in the two cases in Figure 6, increasing the $\mathrm{H}_{2} \mathrm{~S}$ concentration resulted in an increase in the 1 -octanol conversion from $77 \%$ to $95 \%$, but a decrease in the initial phenol conversion from $55 \%$ to $36 \%$. It has previously been described that co-feeding $\mathrm{H}_{2} \mathrm{~S}$ during $\mathrm{HDO}$ on $\mathrm{MoS}_{2}$ type catalysts results in a competitive adsorption of $\mathrm{H}_{2} \mathrm{~S}$ and the oxy-compound [24,46,55,59]. Based on DFT calculations, Badawi et al. [23] found that the adsorption of $\mathrm{H}_{2} \mathrm{~S}$ and $\mathrm{H}_{2} \mathrm{O}$ was stronger on CoMoS sites compared to phenol and these species therefore have an inhibiting effect on the catalyst. This could explain why the phenol conversion decreased when increasing the $\mathrm{H}_{2} \mathrm{~S}$ concentration. Maybe, 1-octanol and $\mathrm{H}_{2} \mathrm{~S}$ adsorb at a similar strength and the conversion 
of 1-octanol therefore increases as this readily adsorbs on the catalytic surface while phenol does not, leaving more active sites for 1-octanol.

\subsection{The effect of water}

To test the stability of the $\mathrm{Ni}-\mathrm{MoS}_{2} / \mathrm{ZrO}_{2}$ catalyst in the presence of water, a series of experiments were carried out by co-feeding water with a separate feed line. Three experiments were made with $\mathrm{H}_{2} \mathrm{O} / \mathrm{H}_{2} \mathrm{~S}$ ratios of $9.7,16$, and 46 , with the ratios calculated in the gas phase assuming complete conversion of DMDS to $\mathrm{H}_{2} \mathrm{~S}$, these results are shown in Figure 9.

The highest $\mathrm{H}_{2} \mathrm{O} / \mathrm{H}_{2} \mathrm{~S}$ ratio of 46 was with 33 vol\% $\mathrm{H}_{2} \mathrm{O}$ in the feed, which corresponds to a bio-oil with a high content of water (the typical water content is ca. $25 \mathrm{wt} \%[60,61]) .2$ vol\% DMDS was added to the feed oil in this case, as this was found sufficient to maintain a decent activity of the catalyst in the stability experiments in Section 3.2. In the experiment, the DOD started at $58 \%$, but during the $96 \mathrm{~h}$ of TOS, the catalyst lost most of its activity, ending at a DOD of $16 \%$, i.e. a relative decrease of $74 \%$ in the DOD.

In an attempt to improve the stability of the catalyst, the content of DMDS in the feed oil was increased to 5 vol\% and the catalyst loading was increased, but the feed water concentration was maintained at 33 vol\%, giving a $\mathrm{H}_{2} \mathrm{O} / \mathrm{H}_{2} \mathrm{~S}$ ratio of 16 . This increased the stability of the catalyst somewhat, with the relative drop in the DOD now being $48 \%$ (see Figure 9). The generally higher DOD activity in this case was due to the lower WHSV in this experiment.

Trying to increase the stability even further, the oil/water feed ratio was increased by increasing the oil feed rate, giving an effective water concentration of $20 \mathrm{vol} \%$ and a $\mathrm{H}_{2} \mathrm{O} / \mathrm{H}_{2} \mathrm{~S}$ ratio of 9.7 . In this case, the DOD decreased from $58 \%$ to $38 \%$ (a relative decrease of $36 \%$ ) throughout the $92 \mathrm{~h}$ of testing. This experiment displayed the best stability of the investigated cases.

Comparing the activity in the case of co-feeding water in Figure 9 to the case not cofeeding water in Figure 6(b), the activity decreased significantly when introducing water. This is consistent with previous studies, where it has been concluded that $\mathrm{H}_{2} \mathrm{O}$ competes 
for the same active sites on the $\mathrm{MoS}_{2}$ [23]. This inhibiting effect is elaborated on in Section 3.7.

Calculating the Gibbs free energy for reactions between bulk MoS 2 and water at the given conditions (see ESI for elaboration), showed that $\Delta \mathrm{G}$ is positive for all relevant reactions, indicating that oxidation of the molybdenum by water should not readily take place. This was supported by quantification of the sulfur on the used catalysts, as this was similar comparing cases with $\mathrm{H}_{2} \mathrm{O} / \mathrm{H}_{2} \mathrm{~S}$ ratios varying from 0 to 46 (see Table 1). Mo $\mathrm{Ka}_{1,2}$ / $\mathrm{S} \mathrm{Ka}_{1,2} \mathrm{X}$-ray emission peaks ratio for catalysts exposed to 2 vol\% DMDS without cofeeding water and in the case of $\mathrm{H}_{2} \mathrm{O} / \mathrm{H}_{2} \mathrm{~S}=46$ was also found to be similar (see Figure 7).

Badawi et al. [24] showed by DFT calculations that it is the stability of the sulfur atoms located along the edges of the $\mathrm{MoS}_{2}$ slabs which are least stable in the structure, as this is the dynamic part of the system. In their calculations, they found that a $\mathrm{H}_{2} \mathrm{O} / \mathrm{H}_{2} \mathrm{~S}$ ratio above 40 resulted in exchange of sulfur with oxygen (S-O exchange) along the slab edges. However, the results of Figure 9 indicate that this threshold is even lower.

\subsection{The effect of potassium}

To test the influence of potassium, Ni-MoS$/ 2 \mathrm{ZrO}_{2}$ was impregnated with $\mathrm{KNO}_{3}$ to a molar ratio of $\mathrm{K} /(\mathrm{Ni}+\mathrm{Mo})$ of 1 . The resulting catalyst was tested with a feed of $50 \mathrm{~g} / \mathrm{l}$ phenol and 2 vol\% DMDS in 1-octanol, i.e. similar to the experiment presented in Figure 6(b). The development in the DOD and the conversion of phenol and 1-octanol in this experiment is shown in Figure 10. The DOD rapidly stabilized at ca. 5\% and remained at this level for the duration of the $46 \mathrm{~h}$ experiment There was practically no activity for phenol deoxygenation and the conversion was $<2 \%$, with the primary product being octyl phenol. This reaction was probably facilitated by the $\mathrm{ZrO}_{2}$ and catalyzed by its acid sites [51].

Comparing these results to the reference case in Figure 6(b), the DOD was about 80\% lower, showing severe loss of activity of the catalyst when poisoned by potassium. Similarly, Kubicka and Horacek [58] found that the primary source of deactivation of Co$\mathrm{MoS}_{2} / \gamma-\mathrm{Al}_{2} \mathrm{O}_{3}$ for $\mathrm{HDO}$ of waste rapeseed oil was deposition of alkali metals on the active sites. Andersen et al. [62] made DFT calculations on the influence of potassium doping on $\mathrm{MoS}_{2}$ for $\mathrm{CO}$ hydrogenation. Their results showed that potassium readily binds to the 
edges of the MoS 2 slabs, blocking both Mo and $\mathrm{S}$ sites. This means that $\mathrm{CO}$ dissociation could not take place on the catalyst and $\mathrm{H}_{2}$ dissociation was limited at the edges as well. This indicates that also for HDO on MoS 2 type catalysts the vacancy sites on the slab edges are readily blocked by potassium and consequently the HDO activity is suppressed, as found in the present study.

\subsection{The effect of chlorine containing components}

For testing the influence of chlorine containing components on the stability of the catalyst, 0.3 vol\% 1 -chlorooctane (corresponding to $0.05 \mathrm{wt} \% \mathrm{Cl}$ ) was added to a feed of $50 \mathrm{~g} / \mathrm{l}$ and $2 \mathrm{vol} \%$ DMDS in 1-octanol, simulating a typical chlorine concentration in bio-oil [53]. 1-chlorooctane is as such not a typically occurring molecule in bio-oil, but it was chosen to be comparable to the thiol addition investigated in Section 3.3.

Figure 11 shows the development in the conversion of phenol and 1-octanol and the yields of the primary products as a function of TOS. Comparing the activity in the current case to the similar case without chlorine in the feed (see Figure $6(\mathrm{~b})$ ), the conversion of 1 octanol dropped from ca. $91 \%$ in the chlorine free case to ca. $74 \%$ with 1 -chlorooctane in the feed. However, this conversion was stable throughout the $52 \mathrm{~h}$ of exposure to the chlorine containing component. This indicates that chlorine is not deactivating the catalyst, but rather competitively inhibiting the active sites. Probably, chlorine competes with the oxy-compounds for the active sites, similar to $\mathrm{H}_{2} \mathrm{O}$ and $\mathrm{H}_{2} \mathrm{~S}$.

The octene/octane ratio in the oil product increased from ca. 0.06 in the chlorine free case to 0.2 when co-feeding chlorine. Thus, it appears that the chlorine containing component inhibits hydrogenation sites more pronounced than the dehydration sites. This may be due to only partial dehydration on the support [51]. Similar to 1-octanol, also the phenol conversion dropped when the catalyst was exposed to 1-chlorooctane. Comparing to the chlorine free case, the conversion of phenol dropped from ca. $25 \%$ to ca. $10 \%$ when feeding 1-chlorooctane. The drop in the phenol conversion is therefore more pronounced than that of 1 -octanol. The conversion of phenol was still stable throughout the exposed time frame. The higher drop in the phenol conversion compared to 1-octanol is related to the inhibiting effect on the hydrogenation sites, as the HDO of phenol partly is dependent on the hydrogenation of the aromatic ring before deoxygenation (see Figure 5). 
In the experiment, the conversion of 1-chlorooctane to octene/octane and $\mathrm{HCl}$ was ca. $40 \%$. $\mathrm{Cl}$ ions were identified in the aqueous phase product by precipitation of $\mathrm{AgCl}$ with $\mathrm{AgNO}_{3} .40 \%$ conversion of 1-chlorooctane in the feed containing 0.3 vol\% 1-chlorooctane corresponds to a release of $\mathrm{Cl}$ atoms relative to Mo atoms on the catalyst in a ratio of 1.1 mol Cl per mol Mo over the $52 \mathrm{~h}$ TOS. Yet, the catalyst did not appear to suffer from continuous deactivation.

After $52 \mathrm{~h}$ of TOS the 1-chlorooctane was removed from the feed. At this point, the activity immediately started to increase (see Figure 11) toward the activity level of the unpoisoned catalyst (see Figure 6(b)). This proves that the chlorine deactivation is reversible on Ni-MoS2. During the start of the experiment the chlorine deactivation was established within the first $9 \mathrm{~h}$ of TOS, however re-establishing the activity after removing the chlorine from the feed was a slow process in comparison, taking more than $20 \mathrm{~h}$.

\subsection{Inhibition strength of $\mathrm{H}_{2} \mathrm{~S}, \mathrm{H}_{2} \mathrm{O}$, and chlorine}

From Section 3.3, 3.4, and 3.6, it follows that the presence of $\mathrm{H}_{2} \mathrm{~S}, \mathrm{H}_{2} \mathrm{O}$, and/or chlorine inhibits the activity of the catalyst and especially the activity for HDO of phenol. To further quantify this, the experimental data was fitted to a kinetic model. HDO of model compounds such as phenol has previously been shown to follow $1^{\text {st }}$ order kinetics $[35,41-$ 43], indicating that the adsorption of the reactant is rate determining. Thus, it would also be a fair assumption that the surface of the catalyst has a low coverage of the reactant while predominantly being saturated by other compounds in the feed. Considering the different species as inhibitors competing for the active sites on the catalyst, the $1^{\text {st }}$ order rate constants can be expressed by the availability of free sites, in a Langmuir-Hinshelwood kinetic model $[63,64]$ :

$$
\boldsymbol{k}_{i, e f f}=\boldsymbol{k}_{0, i} \cdot \boldsymbol{\theta}_{*}
$$

Here, $k_{e f f}$ is the effective rate constant for reaction $i$ measured in the experiment, $k_{0}$ is the rate constant for reaction $i$ of a catalyst with no inhibiting/deactivating species, and $\theta_{*}$ is the fraction of free sites. If it is assumed that $\theta_{*}$ only varies with the concentration of the impurity (i.e. nearly empty surface with respect to oxygenates), but otherwise is similar across the experiments, this is given by:

$$
\boldsymbol{\theta}_{*}=\mathbf{1}-\boldsymbol{\theta}_{H}-\boldsymbol{\theta}_{S H}-\boldsymbol{\theta}_{O H}-\boldsymbol{\theta}_{C l}
$$


Here, $\theta_{H}, \theta_{O H}, \theta_{S H}$, and $\theta_{C l}$ are the fractional coverage of respectively $\mathrm{H}, \mathrm{OH}, \mathrm{SH}$ and $\mathrm{Cl}$ on the catalyst. These coverages are assumed to be determined from the reactions:

$$
\mathrm{H}_{2} \mathrm{~S}+2^{*} \leftrightharpoons \mathrm{H}^{*}+\mathrm{SH}^{*}
$$

$$
\mathrm{H}_{2} \mathrm{O}+2^{*} \leftrightharpoons \mathrm{H}^{*}+\mathrm{OH}^{*}
$$

$$
\begin{aligned}
& \mathrm{HCl}+2^{*} \leftrightharpoons \mathrm{H}^{*}+\mathrm{Cl}^{*} \\
& \mathrm{H}_{2}+2^{*} \leftrightharpoons 2 \mathrm{H}^{*}
\end{aligned}
$$

Assuming these reactions are in quasi equilibrium, the coverages of the species can be found as:

$$
\boldsymbol{\theta}_{i}=\frac{K_{i} \cdot P_{i}}{\sqrt{K_{H_{2}} \cdot P_{H_{2}}}} \cdot \theta_{*}
$$

Here, $K_{i}$ is the adsorption constant for the coverage of species $i$ and $P_{i}$ the partial pressure of species $i$. Index $i$ represent either $\mathrm{H}_{2} \mathrm{O}, \mathrm{H}_{2} \mathrm{~S}$, or $\mathrm{HCl}$. Thus, $\theta_{*}$ becomes:

$$
\theta_{*}=\frac{1}{1+\sqrt{K_{H_{2}} \cdot P_{H_{2}}}+\frac{K_{H_{2}} S^{\cdot P} H_{2} S}{\sqrt{K_{H_{2}} \cdot P_{H_{2}}}}+\frac{K_{H_{2}}{ }^{\cdot P} H_{2} O}{\sqrt{K_{H_{2}} \cdot P_{H_{2}}}}+\frac{K_{H C l} \cdot P_{H C l}}{\sqrt{K_{H_{2}} \cdot P_{H_{2}}}}}
$$

$\sqrt{K_{H_{2}} \cdot P_{H_{2}}}$ was assumed constant and equal in all experiments in these calculations.

To quantify the parameters of the model described above, activity data was used from the different experiments at a similar TOS (close to $10 \mathrm{~h}$ ) to have a catalyst which had experienced approximately similar wear. The comparison point was chosen at an early point in the experimental series to avoid to severe irreversible catalyst deactivation by sintering, sulfur leaching, coke deposition or similar. Using the two experiments with different concentrations of feed sulfur presented in Section 3.1, data for the case with water addition at a $\mathrm{H}_{2} \mathrm{O} / \mathrm{H}_{2} \mathrm{~S}$ ratio of 9.7 presented in Section 3.4, and the experiment with chlorine addition presented in Section 3.6 the equation system of four variables was solved for the phenol based activity data as a sum of square minimization between differences in $k_{P h, e f f}$ and $k_{P h \text {,app }}$ and the solution is summarized in Table 2; note that the total partial pressure of chlorine containing species (estimated from the feed concentrations of 1 -chlorooctane) were used in this analysis. From this analysis, $K_{\mathrm{H}_{2} S}$ and 
$K_{\mathrm{H}_{2} \mathrm{O}}$ were almost identical, differing by less than a factor of 1.5 which is within the experimental uncertainty. Contrary, $K_{\mathrm{HCl}}$ was two orders of magnitude higher than both $K_{\mathrm{H}_{2} \mathrm{~S}}$ and $K_{\mathrm{H}_{2} \mathrm{O}}$. Thus, chlorine was by far the strongest poison of the investigated species. From the analysis of $\mathrm{Cl}$ poisoning in Section 3.6, this strong effect of chlorine was not immediately apparent, but this was because the low feed concentration of chlorine, lead to in a low partial pressure of chlorine in this experiment (see Table 2).

A similar kinetic analysis was not done for the 1-octanol HDO reaction because this appeared to be mass transport limited in some of the cases (see ESI for details).

As $\mathrm{ZrO}_{2}$ previously has been reported to exhibit a low activity at the current conditions [51] and $\mathrm{Ni} / \mathrm{ZrO}_{2}$ is inactive for $\mathrm{HDO}$ under sulfiding conditions [7], the results in Table 2 reflect that the changes in activity must mainly be due to changes in the NiMoS 2 phase. This change is very likely related to the number of available active sites, as initially assumed.

In conclusion, the results show that the strength of poisoning of the investigated species qualitatively is given as:

Chlorine $>>\mathrm{H}_{2} \mathrm{O} \approx \mathrm{H}_{2} \mathrm{~S}$

In a broader context, $\mathrm{H}_{2} \mathrm{~S}, \mathrm{H}_{2} \mathrm{O}, \mathrm{CO}$, and $\mathrm{NH}_{3}$ are all inhibitors of sulfide catalysts as they compete for the active sites [23,46,59,65]. Badawi et al. [23] found the following order of inhibition for HDO of guaiacol on $\mathrm{MoS}_{2}$ based on DFT calculations:

$$
\mathrm{CO}>\mathrm{H}_{2} \mathrm{~S} \approx \mathrm{H}_{2} \mathrm{O}
$$

Their results also indicate that $\mathrm{H}_{2} \mathrm{~S}$ and $\mathrm{H}_{2} \mathrm{O}$ are roughly equally strong inhibitors. Laurent and Delmon [46] evaluated first order rate constants for a $\mathrm{Ni}-\mathrm{MoS}_{2} / \gamma-\mathrm{Al}_{2} \mathrm{O}_{3}$ catalyst and found the following order of inhibition of the hydrotreating reaction:

$\mathrm{NH}_{3}>\mathrm{H}_{2} \mathrm{~S}>\mathrm{H}_{2} \mathrm{O}$

To put the current work into this perspective, it seems apparent that performing HDO of a real bio-oil with a $\mathrm{Ni}_{-} \mathrm{MoS}_{2}$ based catalyst is a challenge due to the many impurities found in bio-oil. Potassium should be removed prior to the HDO reactor as this is a source of severe and irreversible deactivation (see Figure 10). A guard bed prior to the 
hydrotreating reactor has been proposed to prevent metal deposition [65]. Here metals would be trapped in a porous material like alumina, bauxite, magnesium silicate, clays, or similar. This will however not trap organic bound metals. Alternatively, Bridgwater [60] suggested that nearly all alkali metals can be captured in the ash fraction in the flash pyrolysis plant, and so it is maybe not a question of removing potassium from the bio-oil, but avoiding that it comes there in the first place.

It may not be necessary to remove $\mathrm{H}_{2} \mathrm{~S}, \mathrm{H}_{2} \mathrm{O}$, and $\mathrm{Cl}$ (as organic chlorine or $\mathrm{HCl}$ ) prior to the HDO reactor, but they will decrease the activity of the catalyst as they compete for the active sites. If the content of chlorine is low this can probably be tolerated if the residence time is chosen accordingly. On the other hand, the presence of water needs to be balanced by a sulfur source which could be counterbalanced either by addition of sufficient sulfur (as DMDS, $\mathrm{H}_{2} \mathrm{~S}$, etc.) or by dilution, e.g., by co-feeding with crude oil or recirculation of part of the hydrocarbon product to decrease the water concentration in the feed. Dilution is probably needed for bio-oils with high water contents, as 5 vol\% DMDS was insufficient to maintain stability of an oil with 33 vol\% water in the present work. Addition of such high levels of DMDS seems questionable. The requirement of a sulfur feed will additionally require an increased residence time, both to circumvent the inhibiting effect of $\mathrm{H}_{2} \mathrm{~S}$, but also to ensure that any sulfur containing byproducts which have been formed in the process efficiently are desulfurized again to ensure a sulfur lean product.

\section{Conclusion}

The stability of $\mathrm{Ni}-\mathrm{MoS}_{2} / \mathrm{ZrO}_{2}$ was investigated during $\mathrm{HDO}$ of phenol in 1-octanol, as a bio-oil model compound system. Constant addition of sulfur to the feed was essential to obtain prolonged stable operation of the catalyst, but addition of thiols to the feed in a concentration typically found in bio-oil was insufficient. Instead, DMDS was found to be a good sulfur source during the process if added to the feed in a concentration of $>1$ vol\%. This was supported by STEM-EDX of the catalyst after use which revealed a loss of sulfur from the active phase of the catalyst when co-feeding insufficient amounts of sulfur during HDO. The addition of sulfur to the feed resulted in incorporation of sulfur in the product. Especially unsaturated double bonds (formed from dehydration reactions) were prone to react with $\mathrm{H}_{2} \mathrm{~S}$ to form thiols. Nevertheless, operating at sufficiently high residence time 
$\left(\mathrm{WHSV}<4.9 \mathrm{~h}^{-1}\right)$ reduced the presence of thiols to trace amounts in the oil product due to the catalysts activity for HDS.

Water caused a loss of activity of the catalyst as a function of increasing $\mathrm{H}_{2} \mathrm{O} / \mathrm{H}_{2} \mathrm{~S}$ ratio which should thus be kept lower than at least 10 to obtain a reasonable stability. Even lower ratios may be needed to obtain sufficient stability during prolonged operation (>100 h). While bulk $\mathrm{MoS}_{2}$ is thermodynamically stable towards transformation to the corresponding oxide or oxysulfide, edge sulfur atoms may be replaced by oxygen in the presence of water.

Organically bound chlorine in bio-oil was simulated by adding 1-chlorooctane and a marked loss of activity was observed, probably due to competitive adsorption of the chlorine on the active sites. Removing 1-chlorooctane from the feed restored the activity of the catalyst to a level similar to the un-poisoned case, showing that chlorine poisoning was completely reversible.

A Langmuir-Hinshelwood kinetic approach was applied to quantify the reversible inhibition of $\mathrm{H}_{2} \mathrm{~S}, \mathrm{H}_{2} \mathrm{O}$, and chlorine, which showed that chlorine was by far the strongest inhibitor followed by $\mathrm{H}_{2} \mathrm{O}$ and $\mathrm{H}_{2} \mathrm{~S}$ of roughly equal strength.

Impregnation of $\mathrm{Ni}-\mathrm{MoS}_{2} / \mathrm{ZrO}_{2}$ with $\mathrm{KNO}_{3}$ to a molar a ratio of $\mathrm{K} /(\mathrm{Ni}+\mathrm{Mo})$ of 1 severely decreased the activity of the catalyst. Without potassium a DOD of ca. $90 \%$ was achieved, but after potassium addition the DOD was only ca. $5 \%$. This permanent deactivation is probably caused by occupation of vacancy sites along the MoS2 edges by potassium, blocking the active sites for HDO.

Overall, $\mathrm{Ni}-\mathrm{MoS}_{2} / \mathrm{ZrO}_{2}$ is a prospective catalyst for $\mathrm{HDO}$ of phenol with promising stability, as long as a sufficient co-feed of sulfur is guaranteed. Among the investigated bio-oil impurities, potassium was the worst while $\mathrm{H}_{2} \mathrm{~S}, \mathrm{H}_{2} \mathrm{O}$, and chlorine primarily inhibited the catalyst by competing for the active sites. When using this catalyst, it is recommended to use a high residence time to cope with possible inhibition and, furthermore, to remove potentially formed thiols.

\section{Acknowledgements}

This work is part of the Combustion and Harmful Emission Control (CHEC) research center at the Department of Chemical and Biochemical Engineering at the Technical 
University of Denmark (DTU). The present work is financed by DTU and the Catalysis for Sustainable Energy initiative (CASE), funded by the Danish Ministry of Science, Technology and Innovation. The A. P. Møller and Chastine Mc-Kinney Møller Foundation is gratefully acknowledged for its contribution towards the establishment of the Center for Electron Nanoscopy at the Technical University of Denmark. The research leading to these results has received funding from the European Union Seventh Framework Programme under Grant Agreement 312483 - ESTEEM2 (Integrated Infrastructure Initiative-13).

\section{References}

[1] S. Sorrell, J. Speirs, R. Bentley, A. Brandt, R. Miller, Energ. Policy 38 (2010) 52905295.

[2] S. Joussaume, J. Penner, F. Tangang, Working Group Contribution to the IPCC Fifth Assessment Report Climate Change 2013: The Physical Science Basis, Intergovernmental Panel on Climate Change, 2013.

[3] M. Balat, Energ. Convers. Manage. 52 (2011) 858-875.

[4] A. Roedl, Int. J. Life Cycle Assess. 15 (2010) 567-578.

[5] K. Raffelt, E. Henrich, A. Koegel, R. Stahl, J. Steinhardt, F. Weirich, Appl. Biochem. Biotech. 129 (2006) 153-164.

[6] P.M. Mortensen, J.-D. Grunwaldt, P.A. Jensen, K.G. Knudsen, A.D. Jensen, Appl. Catal. A: Gen. 407 (2011) 1-19.

[7] P.M. Mortensen, D. Gardini, H.W.P. de Carvalho, C.D. Damsgaard, J.-D. Grunwaldt, P.A. Jensen, J.B. Wagner, A.D. Jensen, Catal. Sci. Technol. 4 (2014) 3672-3686.

[8] C. Boscagli, K. Raffelt, T.A. Zevaco, W. Olbrich, T.N. Otto, J. Sauer, J.-D. Grunwaldt, Biomass and Bioenergy 83 (2015) 525-538.

[9] D.C. Elliott, Energy Fuels 21 (2007) 1792-1815.

[10] E. Furimsky, Catal. Today 217 (2013) 13-56.

[11] R.V. Chaudhari, A. Torres, X. Jin, Subramaniam, Ind. Eng. Chem. Res. 52 (2013) 15226-15243.

[12] M. Grilc, B. Likozar, J. Levec, ChemCatChem 8 (2016) 180-191. 
[13] M. Grilc, B. Likozar, J. Levec, Appl. Catal. B: Environ. 150-151 (2014) 275-287.

[14] M. Grilc, B. Likozar, J. Levec, Catal. Today 256 (2015) 302-314.

[15] H. Topsøe, B.S. Clausen, F.E. Massoth, Hydrotreating Catalysis, Springer-Verlag, 1996.

[16] H. Topsøe, K.G. Knudsen, L.S. Byskov, J.K. Nørskov, B.S. Clausen, in:, Science and Technology in Catalysis, Elsevier, 1999, pp. 13-22.

[17] R. Prins, in:, John Wiley \& Sons, Inc.: New York, 2008, pp. 2695-2718.

[18] P. Raybaud, Appl. Catal. A: Gen. 322 (2007) 76-91.

[19] S. Helveg, J.V. Lauritsen, E. Lægsgaard, I. Stensgaard, J.K. Nørskov, B.S. Clausen, H. Topsøe, F. Besenbacher, Phys. Rev. Lett. 84 (2000) 951-954.

[20] R. Prins, Adv. Catal. 46 (2001) 399-464.

[21] J.V. Lauritsen, J. Kibsgaard, S. Helveg, H. Topsøe, B.S. Clausen, E. Laegsgaard, F. Besenbacher, Nat. Nanotechnol. 2 (2007) 53-58.

[22] F. Besenbacher, M. Brorson, B.S. Clausen, S. Helveg, B. Hinnemann, J. Kibsgaard, J.V. Lauritsen, P.G. Moses, J.K. Nørskov, H. Topsøe, Catal. Today 130 (2008) 8696.

[23] M. Badawi, J.-F. Paul, S. Cristol, E. Payen, Catal. Commun. 12 (2011) 901-905.

[24] M. Badawi, J.-F. Paul, S. Cristol, E. Payen, Y. Romero, F. Richard, S. Brunet, D. Lambert, X. Portier, A. Popov, E. Kondratieva, J.M. Goupil, J.E. Fallah, J.-P. Gilson, L. Mariey, A. Travert, F. Mauge, J. Catal. 282 (2011) 155-164.

[25] W. Mu, H. Ben, A. Ragauskas, Y. Deng, Bioenerg. Res. 6 (2013) 1183-1204.

[26] J.K. Nørskov, B.S. Clausen, H. Topsøe, Catal. Lett. 13 (1992) 1-8.

[27] O.I. Senol, E.-M. Ryymin, T.-R. Viljava, A.O.I. Krause, Journal of Molecular Catalysis A: Chemical 277 (2007) $107-112$.

[28] O.I. Senol, T.-R. Viljava, A.O.I. Krause, Applied Catalysis A: General 326 (2007) 236 $-244$.

[29] Q. Bu, H. Lei, A.H. Zacher, L. Wang, S. Ren, J. Liang, Y. Wei, Y. Liu, J. Tang, Q. Zhang, R. Ruan, Bioresource Technol. 124 (2012) 470-477.

[30] E. Furimsky, Appl. Catal. A: Gen. 199 (2000) 144-190.

[31] K.C. Pratt, J.V. Sanders, V. Christov, J. Catal. 124 (1990) 416-432.

[32] M. Breysse, J.L. Portefaix, M. Vrinat, Catal. Today 10 (1991) 489-505. 
[33] V.A. Yakovlev, S.A. Khromova, O.V. Sherstyuk, V.O. Dundich, D.Y. Ermakov, V.M. Novopashina, M.Y. Lebedev, O. Bulavchenko, V.N. Parmon, Catal. Today 144 (2009) 362-366.

[34] V.N. Bui, D. Laurenti, P. Delichére, C. Geantet, Appl. Catal. B: Environ. 111 (2011) 246-255.

[35] P.M. Mortensen, J.-D. Grunwaldt, P.A. Jensen, A.D. Jensen, ACS Catal. 3 (2013) 1774-1785.

[36] E. Laurent, B. Delmon, J. Catal. 146 (1994) 281-291.

[37] A.L. Jongerius, J.R. Copeland, G.S. Foo, J.P. Hofmann, P.C.A. Bruijnincx, C. Sievers, B.M. Weckhuysen, ACS Catal. 3 (2013) 464-473.

[38] H.S. Fogler, Elements of Chemical Reaction Engineering, Prentice Hall: New Jersey, 2006.

[39] W.M. Haynes, ed., CRC Handbook of Chemistry and Physics 92th Edition (Internet Version 2012), CRC Press, 2010.

[40] K. Schofield, Prog. Energ. Combust. 34 (2008) 330-350.

[41] S.J. Hurff, M.T. Klein, Ind. Eng. Chem. Fundam. 22 (1983) 426-430.

[42] P.M. Mortensen, J.-D. Grunwaldt, P.A. Jensen, A.D. Jensen, Catal. Today 259 (2016) 277-284.

[43] M.V. Bykova, S.G. Zavarukhin, L.I. Trusov, V.A. Yakovlev, Kinet. Catal. 54 (2013) 4048.

[44] R.G. Dickinson, L. Pauling, Am. Chem. S. 45 (1923) 1466-1471.

[45] B.S. Gevert, J.-E. Otterstedt, F.E. Massoth, Appl. Catal. 31 (1987) 119-131.

[46] E. Laurent, B. Delmon, Ind. Eng. Chem. Res. 32 (1993) 2516-2524.

[47] T.-R. Viljava, S. Komulainen, T. Selvam, A.O.I. Krause, in:, G.F.F. B. Delmon, P. Grange (Eds.), Hydrotreatment and Hydrocracking of Oil Fractions, Elsevier: Amsterdam, 1999, pp. 145 - 152.

[48] F.E. Massoth, P. Politzer, M.C. Concha, J.S. Murray, J. Jakowski, J. Simons, J. Phys. Chem. B 110 (2006) 14283-14291.

[49] E.-M. Ryymin, M.L. Honkela, T.-R. Viljava, A.O.I. Krause, Appl. Catal. A: Gen. 389 (2010) 114-121.

[50] Q. Bu, H. Lei, A.H. Zacher, L. Wang, S. Ren, J. Liang, Y. Wei, Y. Liu, J. Tang, Q. Zhang, R. Ruan, Bioresource Technol. 124 (2012) 470-477. 
[51] P.M. Mortensen, H.W.P. and de Carvalho, J.-D. and Grunwaldt, P.A. Jensen, A.D. and Jensen, J. Catal. 328 (2015) 208-215.

[52] W.K. Purves, D. Sadava, G.H. Orians, H.C. Heller, in:, Life - The Science of Biology, Seventh edition, Freeman \& Co.:Gordonsville, 2004, pp. 15-389.

[53] T.N. Trinh, P.A. Jensen, H.R. Sørensen, K. Dam-Johansen, S. Hvilsted, Energy \& Fuels 27 (2013) 1399-1409.

[54] Y. Wang, H. Lin, Y. Zheng, Catal. Sci. Technol. In press (2013).

[55] T.-R. Viljava, R.S. Komulainen, A.O.I. Krause, Catal. Today 60 (2000) 83-92.

[56] E.-M. Ryymin, M.L. Honkela, T.-R. Viljava, A.O.I. Krause, Appl. Catal. A: Gen. 358 (2009) 42-48.

[57] M. Badawi, S. Cristol, J.-F. Paul, E. Payen, C. R. Chimie 12 (2009) 754-761.

[58] D. Kubicka, J. Koracek, Appl. Catal. A: Gen. 394 (2011) 9-17.

[59] A.Y. Bunch, X. Wang, U.S. Ozkan, J. Mol. Cat. A: Chem. 270 (2007) 264-272.

[60] A.V. Bridgwater, Biomass Bioeng. 38 (2012) 68-94.

[61] D. Meier, B. van de Beld, A.V. Bridgwater, D.C. Elliott, A. Oasmaa, F. Preto, Renew. Sust. Energ. Rev. 20 (2013) 619 - 641.

[62] A. Andersen, S.M. Kathmann, M.A. Lilga, K.O. Albrecht, R.T. Hallen, D. Mei, J. Phys. Chem. C 115 (2011) 9025-9040.

[63] I. Chorkendorff, J.W. Niemantsverdriet, Concepts of Modern Catalysis and Kinetics, John Wiley \& Sons, Inc.: New York, 2007.

[64] P. Stoltze, J.K. Nørskov, in:, John Wiley \& Sons, Inc.: New York, 2008, pp. 14791492.

[65] E. Furimsky, F.E. Massoth, Catal. Today 52 (1999) 381-495. 


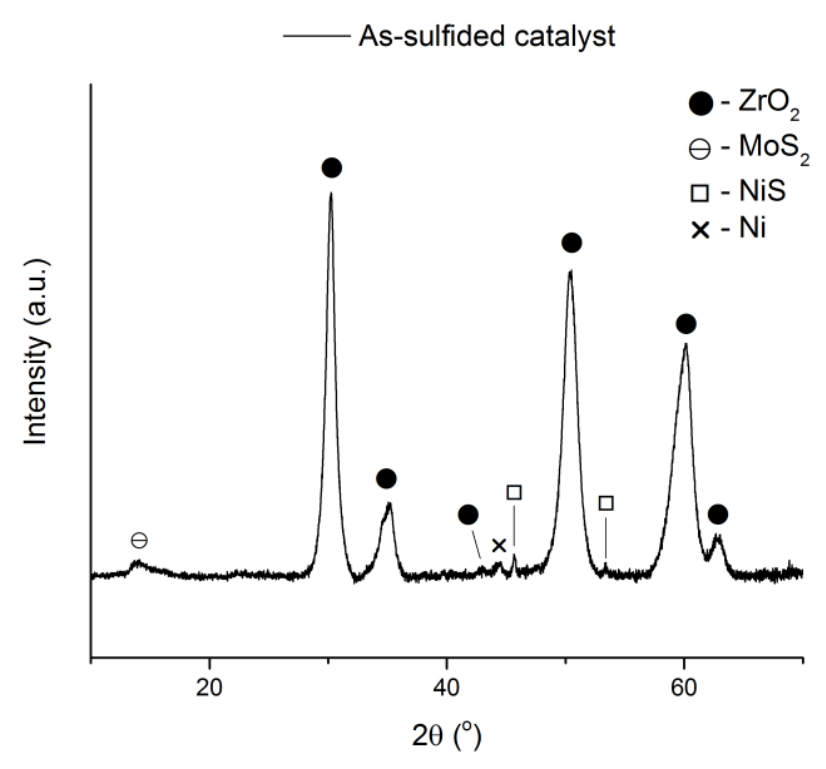

(a) XRD diffraction pattern

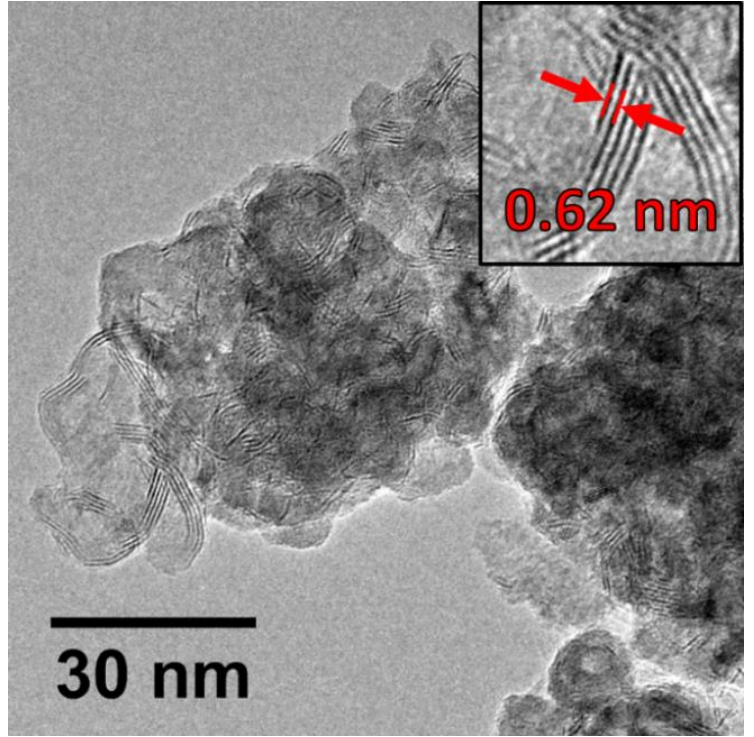

(b) BF-TEM micrograph

Figure 1: Characterization of $\mathrm{Ni}-\mathrm{MoS}_{2} / \mathrm{ZrO}_{2}$ as sulfided catalysts by (a) X-ray diffraction and (b) TEM imaging. Inset in (b) shows $\mathrm{MoS}_{2}$ structures with characteristic interlayer distance of $0.62 \mathrm{~nm}$. 


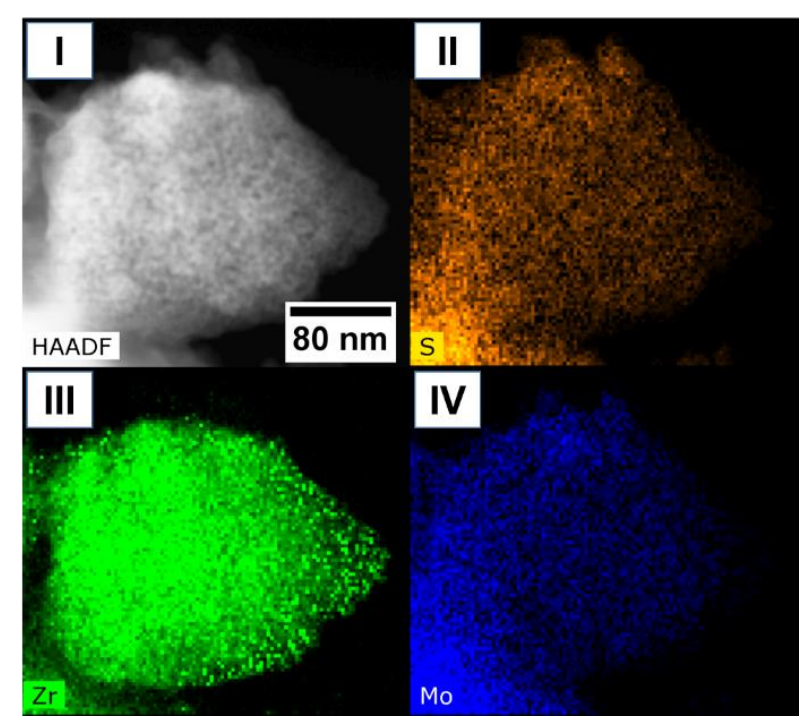

(a) General sulfide coverage

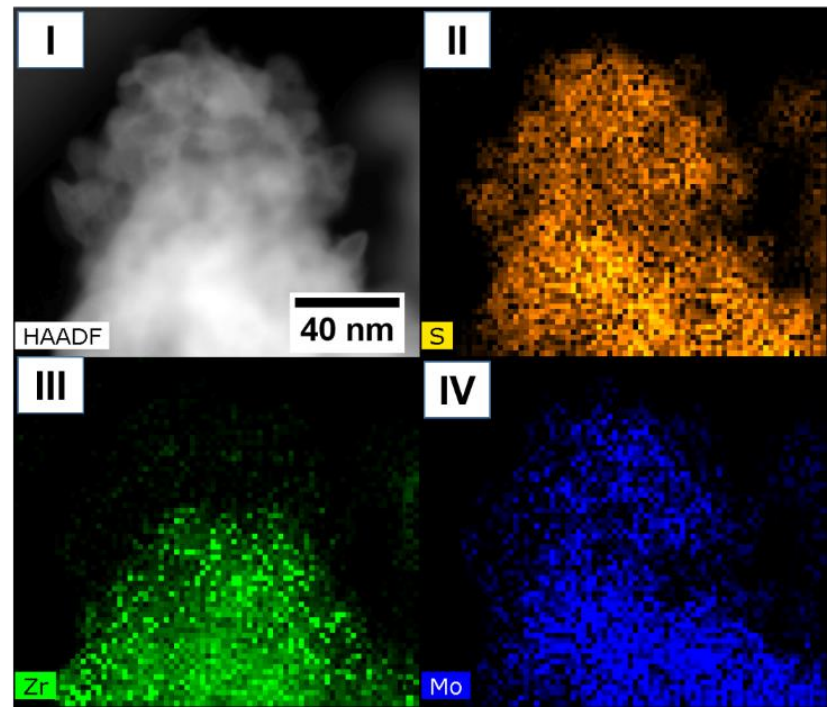

(b) Areas richer in sulfide phase

Figure 2: HAADF-STEM imaging and EDX mapping of $\mathrm{Ni}-\mathrm{MoS}_{2} / \mathrm{ZrO}_{2}$ as-sulfided catalysts presenting (a) general $\mathrm{MoS}_{2}$ coverage and (b) areas richer in sulfide phase. Sub-image (I): Overview of the site in analysis. Sub-images (II) sulfur, (III) zirconium and (IV) molybdenum EDX elemental distributions. 

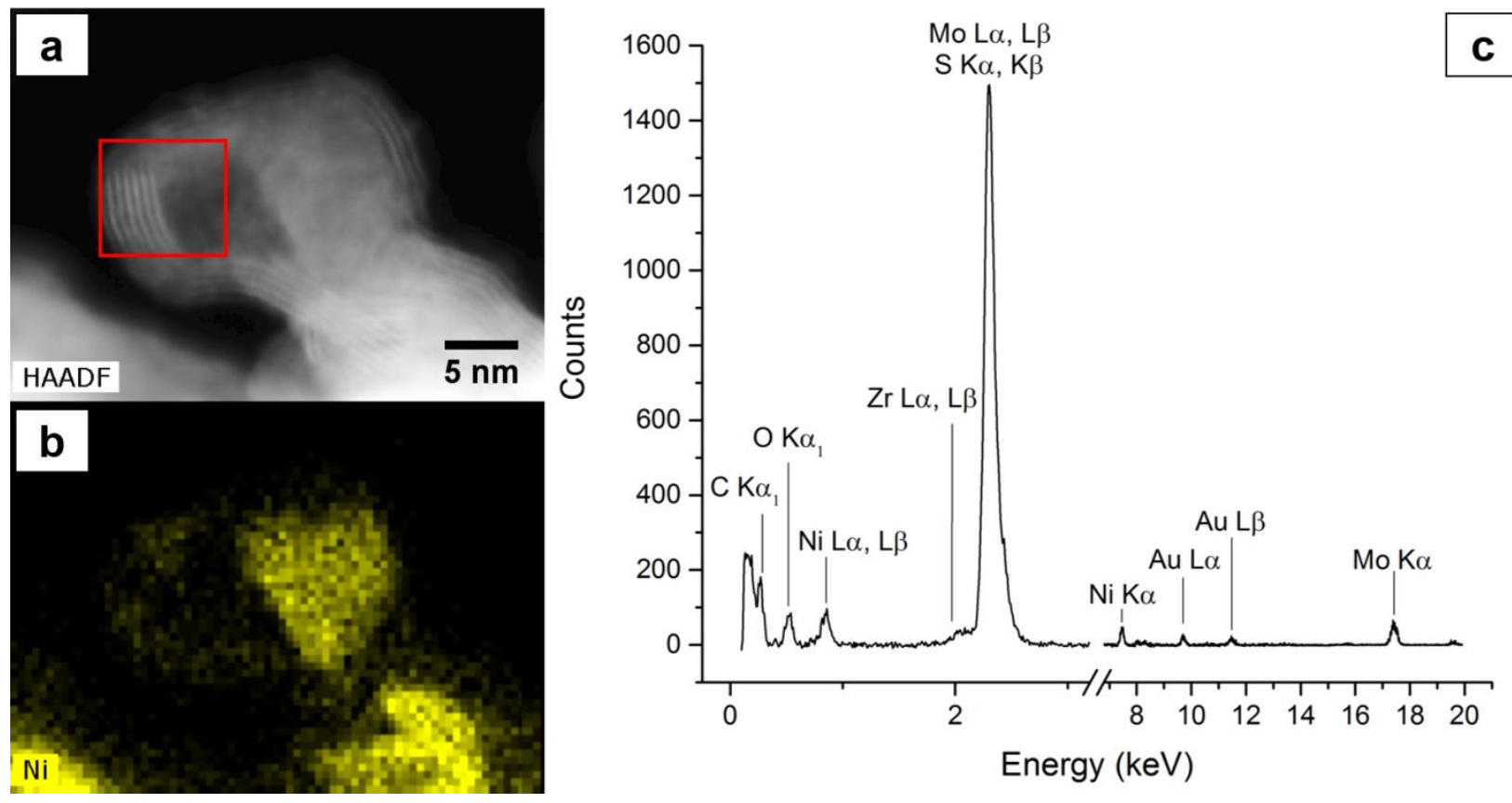

Figure 3: Nickel distribution in the as-sulfided catalyst. Sub-image (a): HAADFSTEM micrograph of the portion of the sample analyzed. In the red box, an area containing $\mathrm{MoS}_{2}$ structures is highlighted. Sub-image (b): Nickel EDX elemental distribution. Sub-image (c): EDX spectrum of the area highlighted in Sub-image (a). 


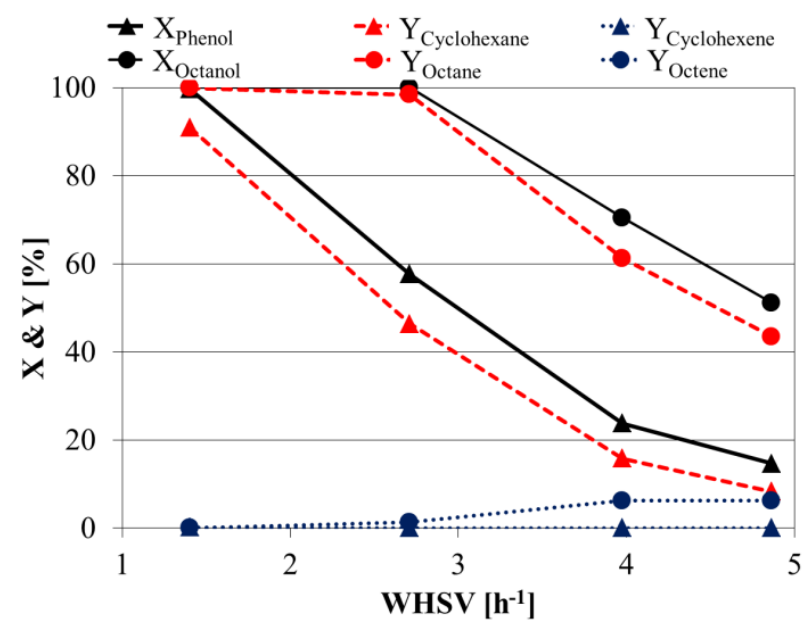

(a) Oil product distribution.

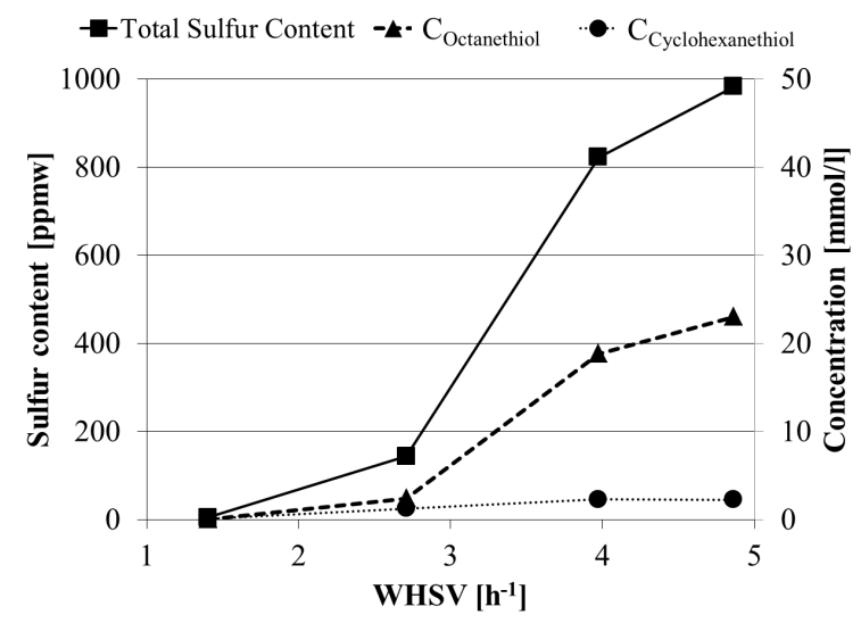

(b) Sulfur content in oil.

Figure 4: Effect of the residence for HDO of $50 \mathrm{~g} / \mathrm{l}$ phenol and 2 vol\% DMDS in 1octanol over Ni-MoS$/ \mathrm{ZrO}_{2}$. (a) Conversions of 1-octanol and phenol and yields of octane, octene, cyclohexane, and cyclohexene and (b) sulfur content in the liquid product. $\mathrm{T}=280^{\circ} \mathrm{C}, \mathrm{P}=100 \mathrm{bar}$. 

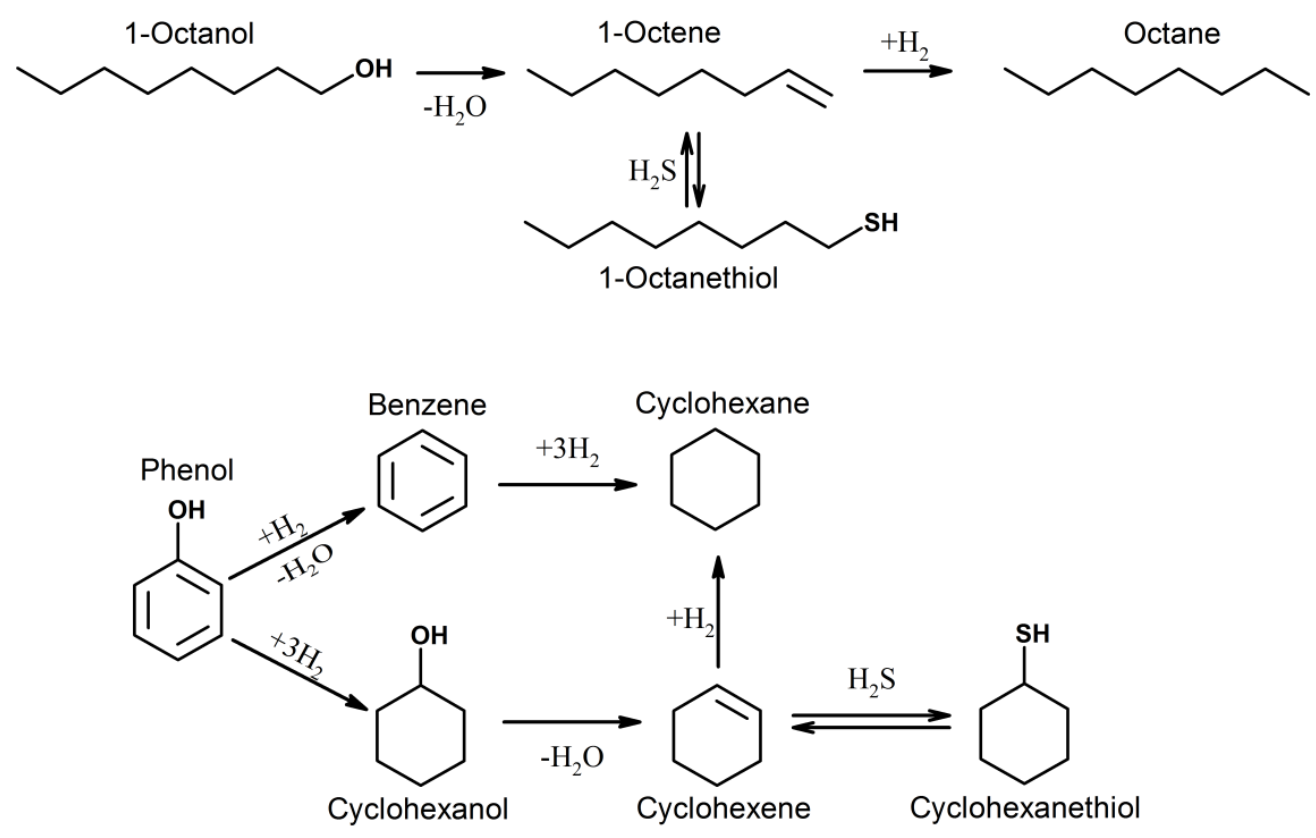

Figure 5: Reaction scheme of 1-octanol and phenol over $\mathrm{Ni}-\mathrm{MoS}_{2} / \mathrm{ZrO}_{2}$. 


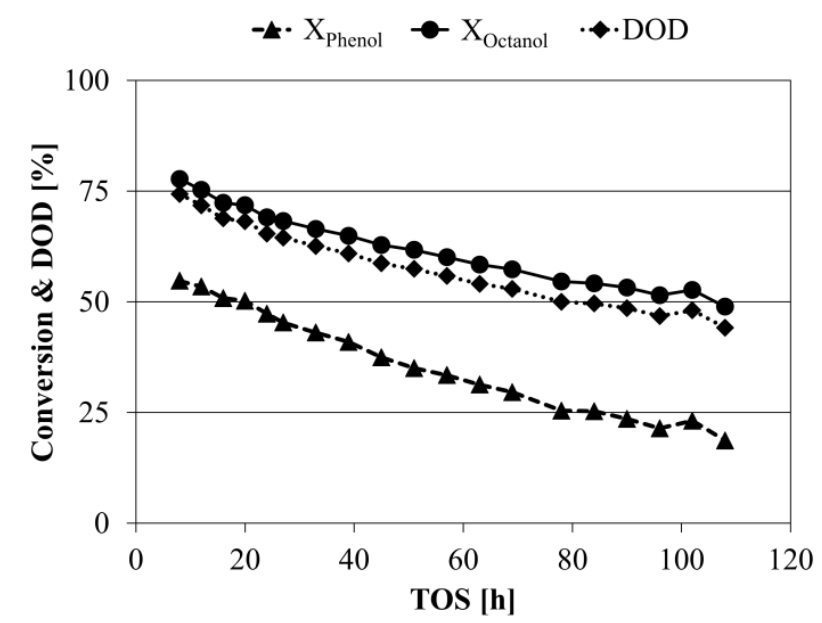

(a) $0.3 \% 1$-octanethiol in the feed.

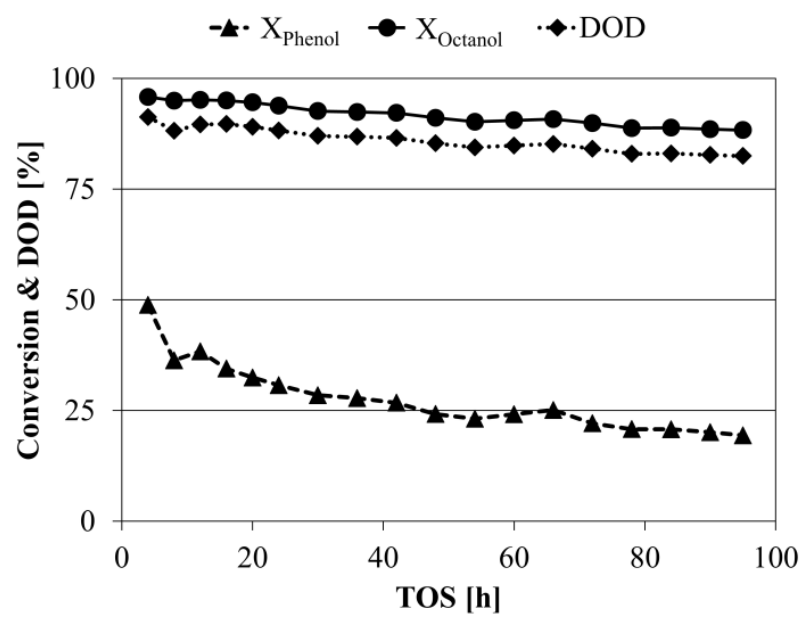

(b) $2 \%$ DMDS in the feed.

Figure 6: Stability of $\mathrm{Ni}-\mathrm{MoS}_{2} / \mathrm{ZrO}_{2}$ during $\mathrm{HDO}$ of phenol and 1-octanol. (a) Conversions of 1-octanol and phenol in a case with 0.3 vol\% 1 -octanethiol in the feed and (b) Conversions of 1-octanol and phenol in a case with $2 \mathrm{vol} \%$ DMDS in the feed. $\mathrm{T}=280^{\circ} \mathrm{C}, \mathrm{P}=100 \mathrm{bar}, F_{\text {oil }}=0.2 \mathrm{ml} / \mathrm{min}, \mathrm{WHSV}=4.0 \mathrm{~h}^{-1}$. 


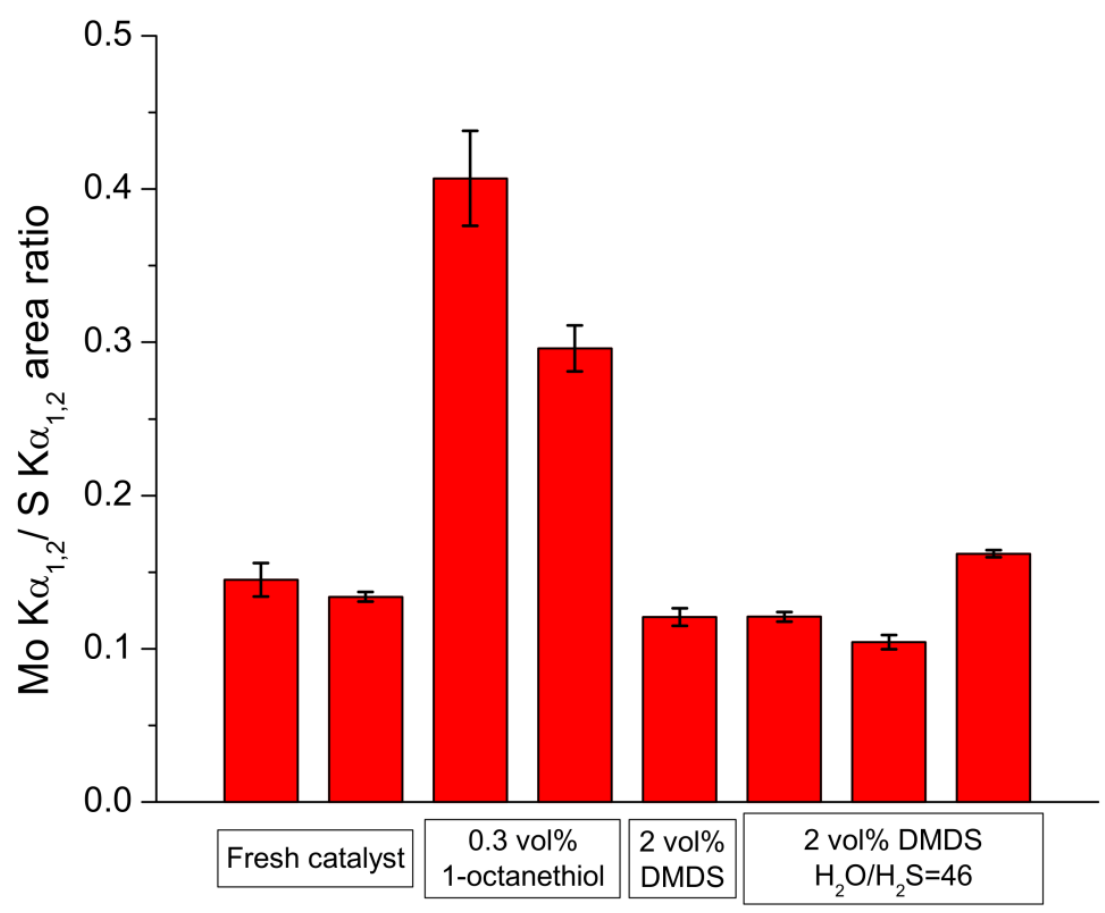

Figure 7: Ratio of the Mo $\mathrm{Ka}_{1,2}$ and $S \mathrm{Ka}_{1,2} \mathrm{X}$-ray emission peak intensities for freshly sulfided $\mathrm{Ni}-\mathrm{MoS}_{2} / \mathrm{ZrO}_{2}$ catalysts and catalyst tested with different sources of sulfur in the feed and varying $\mathrm{H}_{2} \mathrm{O} / \mathrm{H}_{2} \mathrm{~S}$ feed ratios. Multiple data points per catalyst represent measurements carried out in different areas of the same sample. 


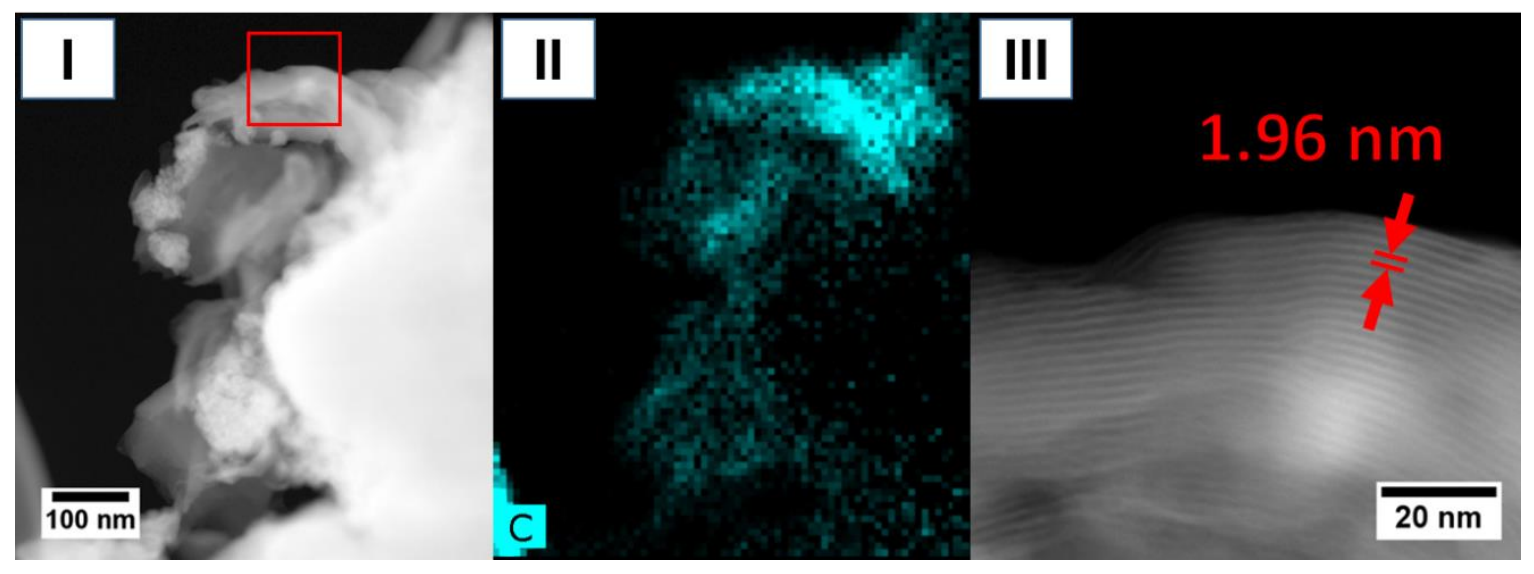

Figure 8: Location and structures of carboneceous deposits in Ni-MoS $/ \mathrm{ZrO}_{2}$ after a hydrodeoxygenation experiment (co-fed with 0.3 vol\% 1-octanethiol). (I): HAADFSTEM micrograph of the area analyzed. (II): carbon EDX elemental distribution. (III): magnified view of the layered structure highlighted in sub-image (I). 


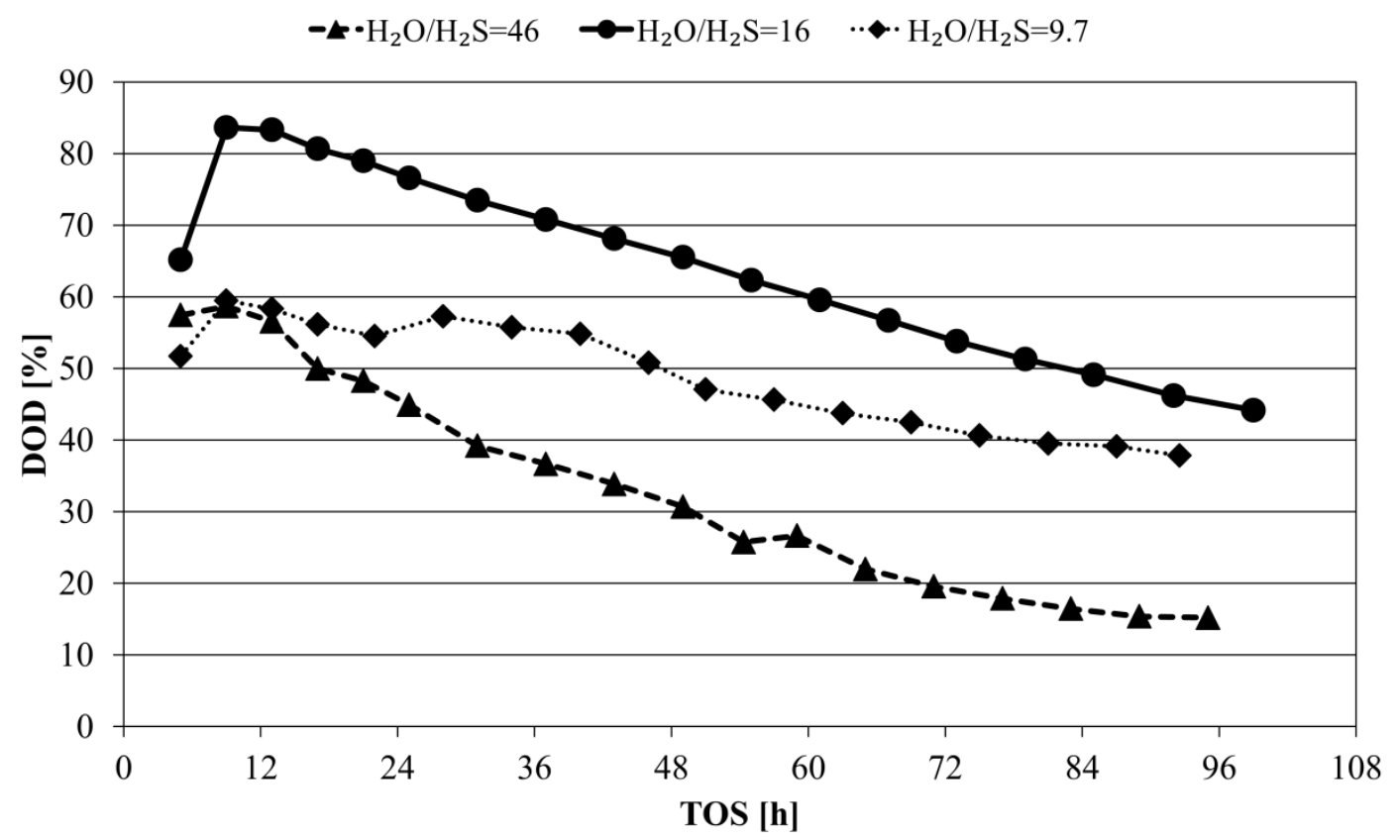

Figure 9: DOD of a phenol/1-octanol feed over a Ni-MoS$/ \mathrm{ZrO}_{2}$ catalyst when cofeeding water. $\mathrm{H}_{2} \mathrm{O} / \mathrm{H}_{2} \mathrm{~S}$ ratio of 46: 2 vol\% DMDS in feed oil, $F_{\text {oil }}=0.2 \mathrm{ml} / \mathrm{min}, F_{\mathrm{H}_{2} \mathrm{O}}=$ $0.07 \mathrm{ml} / \mathrm{min}$, WHSV $=5.8 \mathrm{~h}^{-1} . \mathrm{H}_{2} \mathrm{O} / \mathrm{H}_{2} \mathrm{~S}$ ratio of 16: 5 vol\% DMDS in feed oil, $F_{o i l}=0.2$ $\mathrm{ml} / \mathrm{min}, F_{H_{2} O}=0.07 \mathrm{ml} / \mathrm{min}$, WHSV $=3.5 \mathrm{~h}^{-1} . \mathrm{H}_{2} \mathrm{O} / \mathrm{H}_{2} \mathrm{~S}$ ratio of $9.7: 5 \mathrm{vol} \%$ DMDS in feed oil, $F_{\text {oil }}=0.33 \mathrm{ml} / \mathrm{min}, F_{H_{2} O}=0.07 \mathrm{ml} / \mathrm{min}, \mathrm{WHSV}=5.1 \mathrm{~h}^{-1} . \mathrm{T}=280^{\circ} \mathrm{C}, \mathrm{P}=100$ bar. 


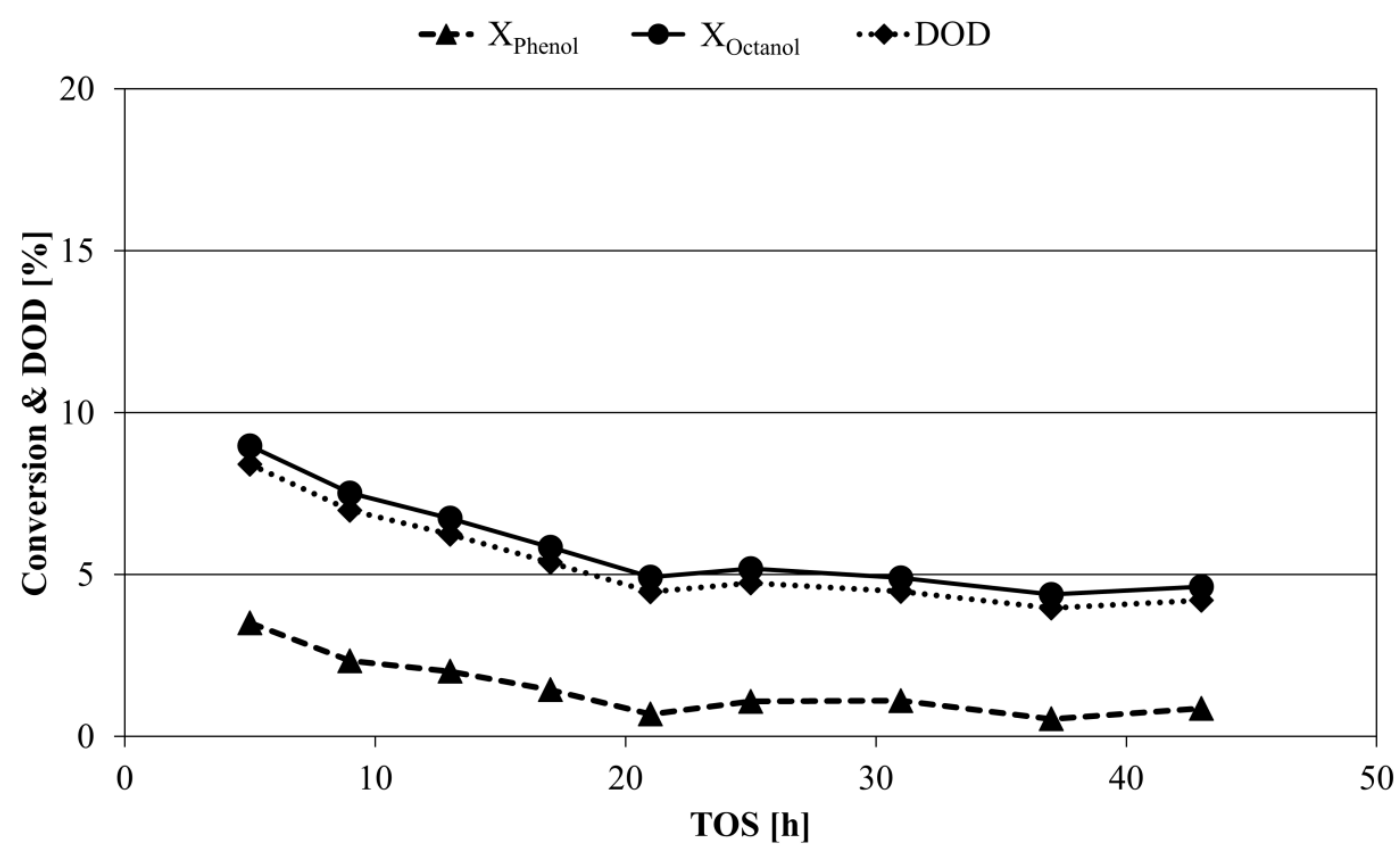

Figure 10: DOD and conversions of phenol and 1-octanol during HDO over a potassium doped $\mathrm{Ni}-\mathrm{MoS}_{2} / \mathrm{ZrO}_{2}$ catalyst. $\mathrm{T}=280^{\circ} \mathrm{C}, \mathrm{P}=100 \mathrm{bar}, F_{\text {oil }}=0.2 \mathrm{ml} / \mathrm{min}$, WHSV $=4.0 \mathrm{~h}^{-1}$, feed: $50 \mathrm{~g} / \mathrm{l}$ phenol and 2 vol\% DMDS in 1-octanol. 


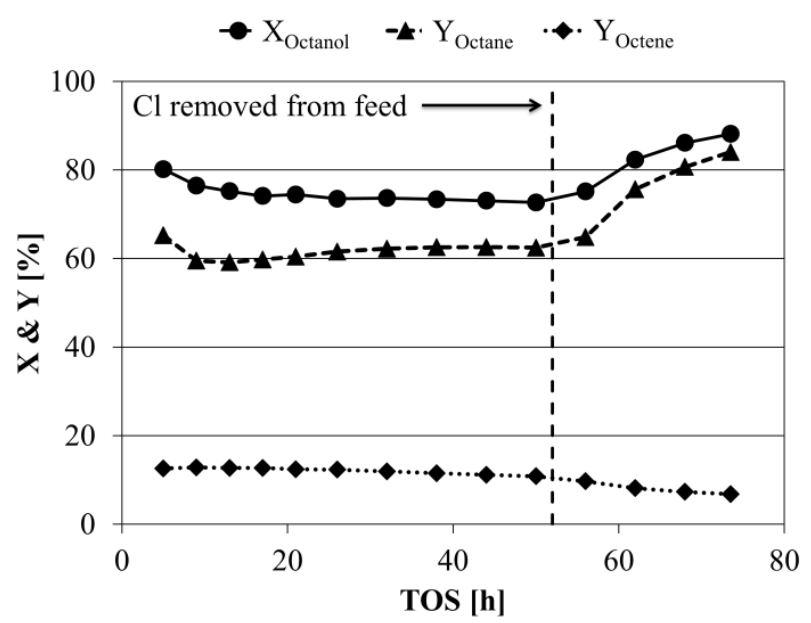

(a) Conversion and yields of 1-octanol related compounds.

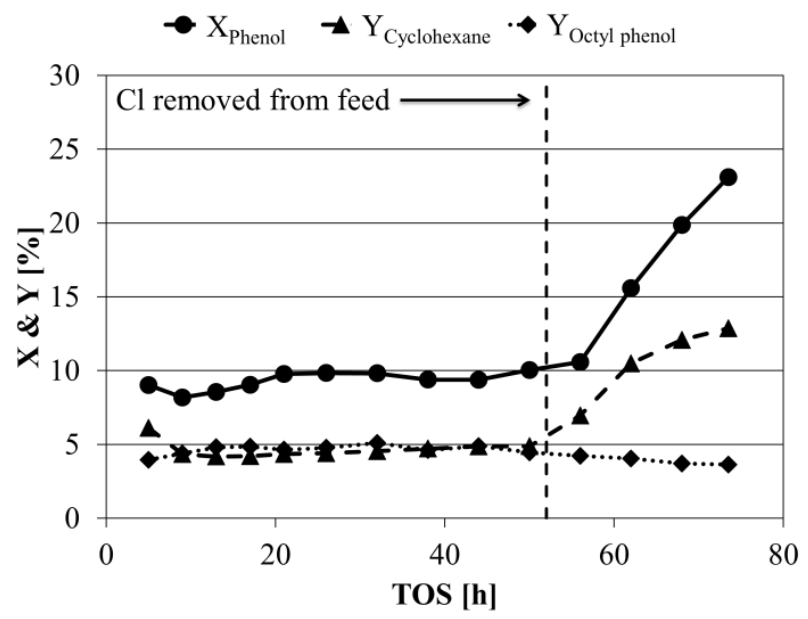

(b) Conversion and yields of phenol related compounds.

Figure 11: Stability of $\mathrm{Ni}-\mathrm{MoS}_{2} / \mathrm{ZrO}_{2}$ during $\mathrm{HDO}$ of phenol and 1-octanol when cofeeding 1-chlorooctane, (a) Conversion and yields of 1-octanol related compounds and (b) conversion and yields of phenol related compounds. The concentration of 1-chlorooctane in the feed was 0.3 vol\%, corresponding to $0.05 \mathrm{wt} \% \mathrm{Cl}$. At $52 \mathrm{~h}$ TOS the 1-chlorooctane was removed from the feed. $\mathrm{T}=280^{\circ} \mathrm{C}, \mathrm{P}=100$ bar, $F_{\text {oil }}=\mathbf{0 . 2}$ $\mathrm{ml} / \mathrm{min}, \mathrm{WHSV}=4.0 \mathrm{~h}^{-1}$, feed: $50 \mathrm{~g} / \mathrm{l}$ phenol, $2 \mathrm{vol} \%$ DMDS, and $0.3 \mathrm{vol} \% 1$ chlorooctane in 1-octanol. 
Table 1: Elemental content of sulfur and carbon on spent catalyst tested with different sources of sulfur in the feed and varying $\mathrm{H}_{2} \mathrm{O} / \mathrm{H}_{2} \mathrm{~S}$ feed ratios. The molar $\mathrm{Ni} /$ Mo ratios of the spent catalysts is also included for reference. Fresh catalyst is a catalyst analyzed directly after sulfidation.

\begin{tabular}{|c|c|c|c|c|c|}
\hline Sulfur in feed & TOS $_{\text {Total }}[\mathrm{h}]$ & $\mathrm{H}_{2} \mathrm{O} / \mathrm{H}_{2} \mathrm{~S}$ ratio & $\mathrm{S}$ [wt\%] & C [wt\%] & $\mathrm{Ni} / \mathrm{Mo}$ \\
\hline \multirow[t]{2}{*}{ As-sulfided } & - & - & 10.9 & 1.9 & 0. \\
\hline & & & & & 27 \\
\hline \multirow[t]{2}{*}{0.3 vol\% 1-octanethiol } & 110 & 0 & 7.5 & 3.7 & 0. \\
\hline & & & & & 21 \\
\hline \multirow[t]{2}{*}{2 vol\% DMDS } & 95 & 0 & 8.4 & 2.0 & 0. \\
\hline & & & & & 27 \\
\hline \multirow[t]{2}{*}{2 vol\% DMDS } & 96 & 46 & 8.9 & 2.1 & 0. \\
\hline & & & & & 22 \\
\hline \multirow[t]{2}{*}{5 vol\% DMDS } & 100 & 16 & 8.2 & 1.7 & 0. \\
\hline & & & & & 23 \\
\hline \multirow[t]{2}{*}{5 vol\% DMDS } & 92 & 9.7 & 8.3 & 3.1 & 0. \\
\hline & & & & & 24 \\
\hline
\end{tabular}


Table 2: Kinetic data and adsorption constants for $\mathrm{H}_{2} \mathrm{~S}, \mathrm{H}_{2} \mathrm{O}$, and chlorine on the $\mathrm{Ni}-\mathrm{MoS}_{2} / \mathrm{ZrO}_{2}$ catalyst. TOS refers to the point of evaluation in the respective experiment. $k_{P h, a p p}$ is the apparent rate constant for phenol conversion and $\boldsymbol{k}_{O c, a p p}$ is the apparent rate constant for 1-octanol conversion as calculated by Eq. 8. The sum of squares for the $k_{P h, e f f}$ relative to $k_{P h, a p p}$ for the reported parameters was 2.4 . $10^{-9}$.

\begin{tabular}{|c|c|c|c|c|c|c|c|c|c|c|}
\hline$i$ & TOS & $\begin{array}{l}p_{\mathrm{H}_{2} S} \\
\text { [bar] }\end{array}$ & $\begin{array}{l}p_{\mathrm{H}_{2} \mathrm{O}} \\
{[\text { bar] }}\end{array}$ & $\begin{array}{r}p_{C l} \\
{[\text { bar }]}\end{array}$ & $\begin{array}{l}\boldsymbol{k}_{\boldsymbol{P h}, \boldsymbol{a p p}} \\
{[\mathrm{ml} / \mathrm{kg} /} \\
\mathrm{min}]\end{array}$ & $\begin{array}{l}\boldsymbol{k}_{\boldsymbol{O} \boldsymbol{c}, \boldsymbol{a p p} \boldsymbol{p}} \\
{[\mathrm{ml} / \mathrm{kg} /} \\
\mathrm{min}]\end{array}$ & \begin{tabular}{l}
\multicolumn{1}{c}{$\boldsymbol{k}_{\mathbf{0}}$} \\
{$[\mathrm{ml} / \mathrm{kg} /$} \\
$\mathrm{min}]$
\end{tabular} & $\begin{array}{l}\frac{K_{H_{2} S}}{\sqrt{K_{H_{2}}}} \\
{\left[\text { bar }^{-}\right.} \\
1 / 2]\end{array}$ & $\begin{array}{l}\frac{K_{H_{2} \mathrm{O}}}{\sqrt{\boldsymbol{K}_{H_{2}}}} \\
{\left[\text { bar }^{-}\right.} \\
\left.{ }_{1 / 2}\right]\end{array}$ & $\begin{array}{r}\frac{K_{H C l}}{\sqrt{K_{H_{2}}}} \\
{\left[\mathrm{bar}^{-1 / 2}\right]}\end{array}$ \\
\hline $\mathrm{H}_{2} \mathrm{~S}$ & 8 & 0.02 & 0 & 0 & 65 & 123 & 67 & 14 & - & - \\
\hline $\mathrm{H}_{2} \mathrm{~S}$ & 8 & 0.5 & 0 & 0 & 36 & 239 & 67 & 14 & - & - \\
\hline $\mathrm{H}_{2} \mathrm{O}$ & 9 & 1.9 & 18 & 0 & 12 & 91 & 67 & 14 & 19 & - \\
\hline $\mathrm{HCl}$ & 9 & 0.5 & 0 & 0.02 & 8 & 109 & 67 & 14 & - & 4360 \\
\hline
\end{tabular}

